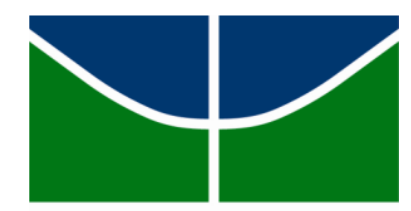

UNIVERSIDADE DE BRASÍLIA

FACULDADE UnB DE PLANALTINA

PROGRAMA DE PÓS-GRADUAÇÃO EM GESTÃO PÚBLICA

MESTRADO PROFISSIONAL EM GESTÃO PÚBLICA

ANDERSON ALLAN ALMEIDA GALVÃO

PLANO DE DESENVOLVIMENTO INSTITUCIONAL: UMA PROPOSTA PARA ELABORAÇÃO E ACOMPANHAMENTO PELOS INSTITUTOS FEDERAIS 
ANDERSON ALLAN ALMEIDA GALVÃO

PLANO DE DESENVOLVIMENTO INSTITUCIONAL: UMA PROPOSTA PARA ELABORAÇÃO E ACOMPANHAMENTO PELOS INSTITUTOS FEDERAIS

Dissertação apresentada ao Programa de Pósgraduação em Gestão Pública da Faculdade UnB de Planaltina da Universidade de Brasília como requisito parcial para obtenção do título de Mestre em Gestão Pública.

Orientador: Prof. Dr. Alexandre Nascimento de Almeida 


\section{PLANO DE DESENVOLVIMENTO INSTITUCIONAL: UMA PROPOSTA PARA ELABORAÇÃO E ACOMPANHAMENTO PELOS INSTITUTOS FEDERAIS}

Dissertação apresentada como requisito parcial para a obtenção do título de Mestre em Gestão Pública pelo Programa de Pós-Graduação em Gestão Pública da Faculdade UnB de Planaltina da Universidade de Brasília.

Aprovado em I

\section{BANCA EXAMINADORA}

Professor Doutor Alexandre Nascimento de Almeida - Orientador Faculdade UnB de Planaltina da Universidade de Brasília

Professora Doutora Annita Valléria Calmon Mendes - Examinadora Interna Faculdade UnB de Planaltina da Universidade de Brasília

Professora Doutora Tatiana de Macedo Soares Rotolo - Examinadora Externa Campus Riacho Fundo do Instituto Federal de Brasília

Professora Doutora Maria Cristina Madeira da Silva - Examinadora Externa - Suplente Campus Planaltina do Instituto Federal de Brasília 
Ficha catalográfica elaborada automaticamente, com os dados fornecidos pelo(a) autor(a)

Galvão, Anderson Allan Almeida

GG182g Plano de Desenvolvimento Institucional: uma $\mathrm{p}$ proposta para elaboração e acompanhamento pelos Institutos Federais / Anderson Allan Almeida Galvão; orientador Alexandre Nascimento de Almeida. -Brasilia, 2016.

$66 \mathrm{p}$.

Dissertação (Mestrado - Mestrado Profissional em Gestão Pública) -- Universidade de Brasília, 2016.

1. plano de desenvolvimento institucional. 2. planejamento. 3. instituto federal. I. Almeida, Alexandre Nascimento de, orient. II. Título. 
Dedico ao meu marido Greisson, pelo companheirismo e incentivo incondicionais, a toda sociedade brasileira, em especial, aos combativos educadores, educadoras e estudantes dos Institutos Federais de Educação, Ciência e Tecnologia. 


\section{AGRADECIMENTOS}

Agradeço a minha mãe Gorett, ao meu pai Edmilson e a minha irmã Karla. Educadores, nordestinos, filhos e neta de agricultores, tiveram na educação a oportunidade de transmutar a aridez do sertão em que nasceram. E, com esforço e sabedoria, puderam me suprir de amor, liberdade e caráter, me apoiando na vida, na lida e nos estudos.

Também sou imensamente grato aos meus ilustres orientadores, Prof. Dr. Elioenai Dornelles Alves (in memoriam) que com generosidade e desprendimento pode transmitir mais que conteúdo acadêmico, um exemplo de vida. Ao Prof. Dr. Alexandre Nascimento de Almeida que, com o espírito de engenheiro e coração educador, mostrou-me, com comprometimento e sabedoria, os caminhos a seguir.

Franqueio minha gratidão a todos os docentes, técnicos, bolsistas e estagiários do Programa de Pós-graduação em Gestão Pública, da Faculdade UnB de Planaltina e da Biblioteca Central da UnB pelo incondicional apoio e pelas inquietações, que me proporcionaram um melhor aprendizado ao longo desta jornada.

Agradeço também aos companheiros que fazem o Sindicato Nacional dos Servidores Federais da Educação Básica, Profissional e Tecnológica (SINASEFE), que incansavelmente lutaram junto ao governo federal pela implantação do Plano de Carreira dos Cargos dos Técnicos-administrativos em Educação (PCCTAE), plano este que hoje me oportuniza apresentar esta dissertação.

De igual maneira sou imensamente grato aos meus colegas da Rede Federal de Educação Profissional, Científica e Tecnológica, em especial aos que estiveram juntos nesta jornada e aos de lida no Instituto Federal de Brasília. O apoio, o aprendizado e o companheirismo de vocês transformaram os obstáculos em oportunidades. Lhes sou imensamente grato pela graça de conviver e aprender com todos vocês. 
A ship in port is safe; but that is not what ships are built for. Sail out to sea and do new things. (Grace Hopper) 


\section{RESUMO}

A pesquisa analisou a execução das metas previstas no Plano de Desenvolvimento Institucional (PDI) do Instituto Federal de Brasília (IFB) elaborado para o período de 2009 a 2013 e as contribuições elencadas pelos gestores da Rede Federal de Educação Profissional, Científica e Tecnológica (Rede Federal), sobre os gargalos encontrados na execução do PDI em suas instituições. A análise do cumprimento das metas foi realizada por meio do confronto das informações constantes no PDI 2009/2013, dos Planejamentos Institucionais e dos Relatórios de Gestão do IFB. Primeiramente, foram elencadas as metas previstas no PDI. Em seguida, foi verificado se as metas constavam no Planejamento Institucional. Por fim, aferiu-se, nos Relatórios de Gestão, se cada meta foi ou não cumprida. Os gargalos do PDI foram identificados por meio da percepção dos gestores da Rede Federal. Para tanto, foi encaminhado, por e-mail, formulário eletrônico com questionário semiestruturado. Para a análise dos dados, utilizou-se a técnica de Análise de Conteúdo que consiste na pré-análise, exploração do material e inferência e interpretação dos resultados. De forma geral, a execução do PDI foi considerada satisfatória, atendendo $72 \%$, das metas. Entretanto, constatou-se que, no mesmo período, novas metas surgiram superestimando em quatro vezes o planejamento inicial. $\mathrm{O}$ resultado da análise de conteúdo apresentou relevantes informações no que se refere aos gargalos encontrados na execução do PDI nos Institutos Federais de Educação, Ciência e Tecnologia (Institutos Federais), sendo predominantes as contribuições relacionadas aos aspectos políticos e institucionais, em especial a preocupação dos gestores com o desconhecimento da comunidade do que venha a ser a própria instituição. Desta forma, a avaliação da execução do planejamento do IFB, bem como, a apresentação dos gargalos identificados pelos gestores servirão de instrumento para a formulação de planejamentos estratégicos factíveis, centrados nas possibilidades e respeitando as peculiaridades existentes nos Institutos Federais.

Palavras-chave: Plano de Desenvolvimento Institucional, planejamento, Instituto Federal 


\begin{abstract}
The research assessed the implementation of the target laid down in the Institutional Development Plan (PDI) of the Federal Institute of Brasília (IFB) drawn up for the period 2009 to 2013 and the contributions listed by the managers of the Federal Network of Professional Education, Science and Technology (Federal Network), about the bottlenecks found in the implementation of the PDI in their institutions. The analysis of the accomplishment of the targets was completed through the confrontation of information contained in the PDI 2009/2013, in Institutional Planning and management reports of the IFB. First, it was listed the targets set in the PDI. Then, it was verified that the targets were in Institutional Planning. Finally, measured in management reports if each target has been accomplished. The PDI bottlenecks were identified through the Federal Networks manager's perception. It was sending for e-mail, electronic form with semi structured questionnaire. For data analysis, we used the technique of Content Analysis involving the pre-analysis, exploration of the material and inference and interpretation of results. In General, the implementation of the PDI was considered satisfactory, given $72 \%$ of the targets. However, it was noted that, in the same period, new targets emerged overestimating in four times the initial planning. The result of the Analysis of Content presented relevant information as regards bottlenecks found in implementation of the PDI in their Federal Institutes, being predominant contributions related to political and institutional aspects, in particular the concern of managers with the unfamiliarity of the community than is the institution. In this way, the evaluation of the implementation of planning the IFB, as well as the presentation of the bottleneck identified by managers, will serve as a tool for formulating feasible strategic planning, focusing on the possibilities and respecting the peculiarities that exist in Federal Institutes.
\end{abstract}

Keywords: Institutional development plan, planning, Federal Institute 


\section{LISTA DE FIGURAS}

Figura 1 - Principais mudanças na Rede Federal no período de 1909 a 1998 ....................... 26

Figura 2 - Distribuição geográfica dos 564 campi dos Institutos Federais em 2016 ............. 27

Figura 3 - Quantidade de unidades da Rede Federal nos seus 107 anos de existência ........... 28

Figura 4 - Distribuição geográfica dos campi do IFB no DF ......................................... 29

Figura 5 - Percepções dos gestores sobre os aspectos políticos e institucionais ................... 46

Figura 6 - Percepções dos gestores sobre os aspectos pedagógicos e metodológicos ............ 49

Figura 7 - Percepções dos gestores sobre os aspectos sociais e culturais .......................... 51

Figura 8 - Percepções dos gestores sobre os aspectos legais e administrativos ....................53

Figura 9 - Respostas à pergunta: com que frequência você faz uso do PDI? ........................ 55

Figura 10 - Respostas à pergunta: qual o seu nível de escolaridade atual? .......................... 56

Figura 11 - Respostas à pergunta: nas suas atividades, você atua na sua área de formação? .57 


\section{LISTA DE TABELAS}

Tabela 1 - Distribuição das 10 dimensões da Lei do SINAES nos cinco eixos de avaliação . 34

Tabela 2 - Distribuição das metas estabelecidas no PDI 2009/2013 do IFB 40

Tabela 3 - Distribuição das metas alcançadas no PDI 2009/2013 do IFB 42

Tabela 4 - Categorização das respostas distribuídas nos quatro aspectos analisados 45 


\section{LISTA DE QUADROS}

Quadro 1 - Perguntas do questionário aplicado aos gestores da Rede Federal ..................... 37 


\section{LISTA DE ABREVIATURAS E SIGLAS}

CEFETs - Centros Federais de Educação Tecnológica

CIS - Comissão Interna de Supervisão

CNE - Conselho Nacional de Educação

COET - Comissão de Ética

CONAES - Comissão Nacional de Avaliação da Educação Superior

CPA - Comissão Própria de Avaliação

CPPD - Comissão Própria de Pessoal Docente

DASP - Departamento Administrativo do Serviço Público

DF - Distrito Federal

EC - Emenda Constitucional

EPCT - Educação Profissional, Científica e Tecnológica

ETF - Escola Técnica Federal

IES - Instituições de Educação Superior

IFB - Instituto Federal de Brasília

IFES - Instituições Federais de Educação Superior

Instituto Federal - Instituto Federal de Educação, Ciência e Tecnologia

INEP - Instituto Nacional de Estudos e Pesquisas Educacionais Anísio Teixeira

LDB - Lei de Diretrizes e Bases

MEC - Ministério da Educação

PCCTAE - Plano de Carreira dos Cargos Técnico-administrativos em Educação

PDCA - Plan, Do, Check and Adjust

PDI - Plano de Desenvolvimento Institucional

PNUD - Programa das Nações Unidas para o Desenvolvimento 
PPA - Plano Plurianual

PRAD - Pró-reitoria de Administração

PRDI - Pró-reitoria de Desenvolvimento Institucional

PREN - Pró-reitoria de Ensino

PREX - Pró-reitoria de Extensão

PrND - Programa Nacional de Desburocratização

PROEP - Programa de Expansão da Educação Profissional

PRONATEC - Programa Nacional de Acesso ao Ensino Técnico e Emprego

Rede Federal - Rede Federal de Educação Profissional, Científica e Tecnológica

SAPIENS - Sistema de Acompanhamento de Processos das Instituições de Ensino Superior

SETEC - Secretaria de Educação Profissional e Tecnológica

SINAES - Sistema Nacional de Avaliação da Educação Superior

SWOT - Strengths, Weaknesses, Opportunities and Threats

TAM - Termo de Acordo de Metas e Compromissos

UNESCO - Organização das Nações Unidas para a Educação, a Ciência e a Cultura 


\section{SUMÁRIO}

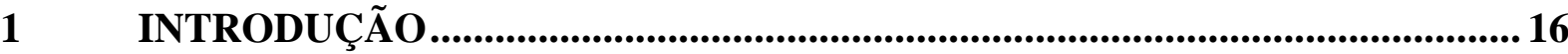

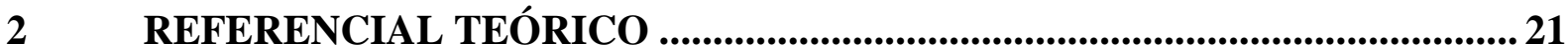

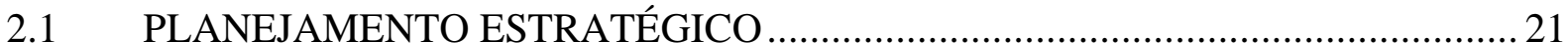

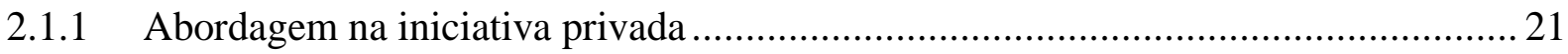

2.1.2 Abordagem nas instituições públicas em geral e nas de ensino .............................. 23

2.2 A REDE FEDERAL DE EDUCAÇÃO PROFISSIONAL ...................................... 24

2.2.1 Evolução da Educação Profissional e Tecnológica............................................... 24

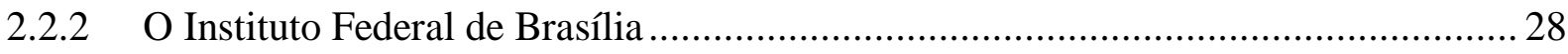

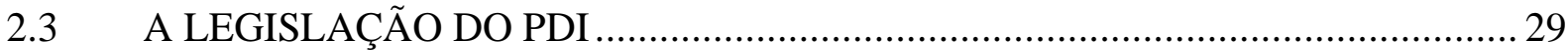

2.3.1 O Sistema Nacional de Avaliação da Educação Superior (SINAES) ....................... 29

2.3.2 O Plano de Desenvolvimento Institucional (PDI) .............................................. 31

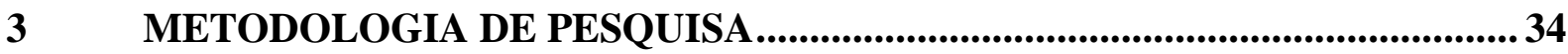

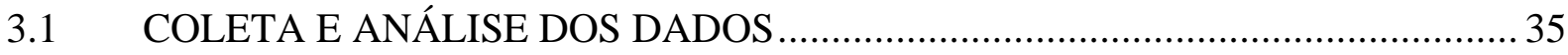

3.1.1 Análise do cumprimento das metas do PDI 2009/2013 do IFB ............................. 35

3.1.2 Identificação dos gargalos encontrados no uso do PDI nos Institutos Federais ......... 36

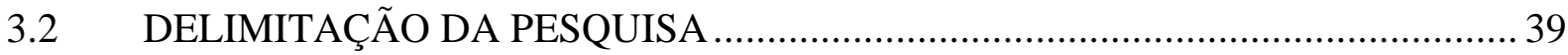

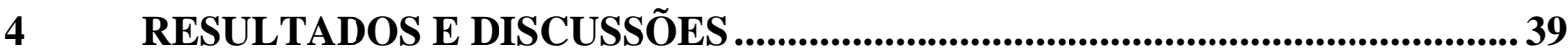

4.1 ANALISANDO AS METAS DO PDI 2009/2013 DO IFB …............................... 39

4.2 IDENTIFICANDO GARGALOS NO PDI DOS INSTITUTOS FEDERAIS .......... 45

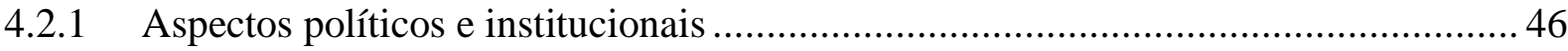

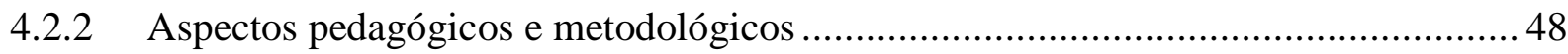

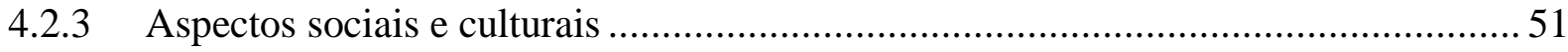

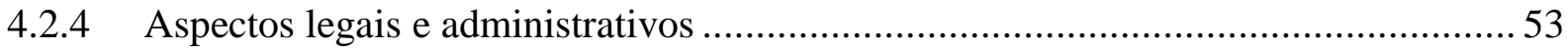

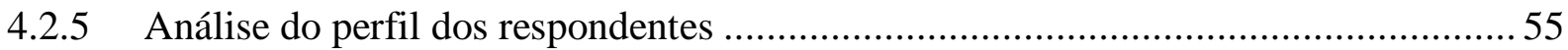

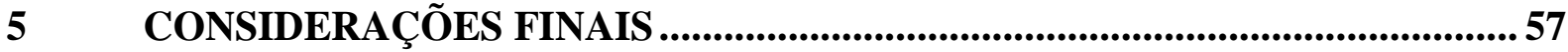

REFERÊNCIAS BIBLIOGRÁFICAS ..................................................................60

APÊNDICE A - RELAÇÃO DE DOCUMENTOS DE PESQUISA.................................. 66 


\section{INTRODUÇÃO}

Na intenção de profissionalizar a administração pública e adequá-la às realidades que se apresentavam, alguns governos se dedicaram a realizar reformas administrativas ao longo da história da República Brasileira.

A primeira reforma administrativa, chamada de "Reforma Burocrática", foi iniciada em 1936 no governo de Getúlio Vargas. Teve como principal característica a criação do Departamento Administrativo do Serviço Público (DASP). Seus principais objetivos foram a centralização, reorganização e a modernização da administração pública brasileira.

Em seguida, em 1956, com o lema de "50 anos em 5", o Plano de Metas do governo de Juscelino Kubistchek, tinha por objetivo dar andamento ao processo de industrialização e de substituição das importações. Este plano se destacou pela expansão da burocracia por meio da criação de novas unidades administrativas descentralizadas.

A partir de 1964, o governo Castello Branco publicou o Decreto-lei No 200/1967 que estabelecia uma série de medidas destinadas à reforma do Estado. Segundo Bresser Pereira (1996), o decreto foi um marco na busca para superar a rigidez da burocracia, além de ser considerado o primeiro contato da Administração Pública Brasileira com o gerencialismo.

No final da década de 1970, foi criado o Programa Nacional de Desburocratização (PrND), cujos principais objetivos eram a revitalização e reorganização das organizações do Estado, a descentralização da autoridade, a melhoria e a simplificação dos processos administrativos e a promoção da eficiência.

A Constituição Federal de 1988 (CF/1988) foi marcada pela suspensão da implantação do modelo de administração gerencial no serviço público. De acordo com Paludo (2012) os mecanismos de controle da CF/1988 favoreceram o controle social, mas o excesso da aplicação do modelo burocrático dificultou a transparência administrativa. 
Por mais que as reformas administrativas implementadas no Brasil entre 1930 e 1995 tenham surtido algum efeito no que tange à modernização da gestão pública brasileira, em decorrência das instabilidades políticas e econômicas vividas neste período, nenhuma das ações ou reformas foram implementadas em sua integralidade.

A segunda reforma administrativa teve início em 1995 com o Plano Diretor da Reforma do Aparelho do Estado (PDRAE), gerido pelo então Ministro da Administração Federal e Reforma do Estado, Luiz Carlos Bresser Pereira, tinha como objetivo a melhoria da eficiência dos serviços públicos por meio da adoção do modelo de administração gerencial.

A legitimação da reforma administrativa proposta por Bresser-Pereira se concretizou por meio da Emenda Constitucional (EC) No 19/1998, tendo como cerne a adoção de um novo modelo de gestão. Saiu-se do modelo Burocrático, regido pelo princípio da legalidade, para o modelo gerencial, pautado pelo princípio da eficiência.

Dando continuidade à Reforma Administrativa, neste mesmo ano foi publicado o Decreto $N^{\circ}$ 2.829/1998, que estabelece normas para a elaboração e execução do Plano Plurianual (PPA) e dos orçamentos da União. O Decreto prevê que para a elaboração e execução do PPA, toda ação finalística deverá ser estruturada em programas orientados para a resolução de problemas e atendimento às demandas da sociedade.

No âmbito da educação, acompanhando a reforma administrativa iniciada em 1995, a Lei No 9.394/1996, mais conhecida como a Lei de Diretrizes e Bases (LDB) da Educação, em seu Art. $9^{\circ}$, incisos VI, VIII e IX, estabelece, sob responsabilidade da União, o processo nacional de avaliação das instituições de Educação Superior. Entretanto, este processo só foi instituído 8 anos depois por meio da Lei $N^{\circ}$ 10.861/2004, que criou o Sistema Nacional de Avaliação da Educação Superior (SINAES). Em seu Art. $3^{\circ}$, o SINAES estabelece o Plano de Desenvolvimento Institucional (PDI) como ferramenta para avaliação das Instituições de Educação Superior (IES). 
Consolidando o PDI como instrumento norteador do planejamento estratégico e de avaliação institucional das IES, o Decreto No 5.773/2006 traz um detalhamento mínimo do que deve constar no documento. Mesmo sendo um documento obrigatório, a legislação permitiu que sua construção fosse livre, garantindo às IES o exercício de sua criatividade e liberdade no processo de sua elaboração. Entretanto, 10 dimensões (eixos temáticos) devem estar presentes, por serem tomados como referenciais das análises a serem realizadas pelo Ministério da Educação (MEC).

Neste contexto de consolidação das políticas de acompanhamento e avaliação da educação superior é que nascem os Institutos Federais de Educação, Ciência e Tecnologia (Institutos Federais), criados por meio do Decreto $N^{\circ} 11.892 / 2008$, juntamente com a Rede Federal de Educação Profissional, Científica e Tecnológica (Rede Federal) vinculando à sua estrutura os Centros Federais de Educação Tecnológica (CEFETs), as Escolas Técnicas vinculadas às Universidades Federais aos Institutos Federais. De acordo com a SETEC (2008), o Instituto Federal “é uma instituição que articula a educação superior, básica e profissional, pluricurricular e multicampi, especializada na oferta de educação profissional e tecnológica em diferentes níveis e modalidades de ensino".

Uma vez que as instituições integrantes da Rede Federal também ofertam cursos de formação superior, ficam obrigadas a elaborar e encaminhar para o MEC, em um prazo máximo de 180 dias, a proposta de Estatuto e o PDI, assegurada a participação da comunidade acadêmica na construção dos documentos.

Neste curto período, tomando por base a recém promulgada Lei $N^{\circ} 10.861 / 2004$, denominada Lei do SINAES, e o Decreto No 11.892/2008, que instituía os Institutos Federais, a equipe de servidores integrantes do quadro de pessoal dos Institutos Federais nas suas respectivas instituições elaborou a proposta do Estatuto das suas instituições e o primeiro PDI para o quinquênio 2009/2013 e apresentou no prazo de 180 dias ao MEC. 
Como uma política ainda em fase de implantação, sem histórico para acompanhamento e avaliação, o primeiro PDI dos Institutos Federais foi elaborado tomando por base as informações orçamentárias destinadas para à Rede Federal, os arranjos produtivos locais, a experiência e as expectativas dos gestores da instituição.

A Rede Federal, em função da forte expansão que vivenciou no período de 2005 a 2015, onde, ampliado suas unidades de 140 para 564, sofreu constantes interferências políticas, o que acarretou em inúmeros replanejamentos e a implementação de políticas públicas que, na época de sua concepção não estavam previstas, como o Programa de Expansão da Rede Federal (PROEP) e o Programa Nacional de Acesso ao Ensino Técnico e Emprego (PRONATEC).

No início de sua implantação, as dificuldades foram uma constante no cotidiano dos gestores, pois, por normativa legal, precisavam utilizar o PDI para orientar o planejamento estratégico de suas ações, mas este documento não conseguia acompanhar a dinamicidade e a realidade de suas instituições.

Neste contexto, esta pesquisa tem como objetivo geral, analisar o planejamento dos Institutos Federais para propor ajustes na elaboração e acompanhamento nas próximas edições do PDIs na expectativa de que venham refletir a realidade, a singularidade e a dinamicidade que se apresenta no planejamento dos nestas instituições.

Para que pesquisa atinja seu propósito, a análise será realizada buscando os seguintes objetivos específicos:

i) analisar o planejamento do IFB através da verificação do cumprimento dos objetivos gerais por meio das metas estabelecidas no PDI 2009/2013 do IFB (Doc 1);

ii) propor ajustes na construção e acompanhamento do PDI, com base nas contribuições elencadas pelos gestores da Rede Federal e na legislação 
pertinente, para que este venha a atender o planejamento estratégico dos Institutos Federais nas suas próximas edições.

O desenvolvimento da pesquisa justifica-se diante da problemática que se apresenta em decorrência do acelerado crescimento da Rede Federal que, a partir da Lei № 11.892/2008, tomou proporções não previstas, tendo um aumento de $136 \%$ no número de unidades no período de 10 anos, sendo que os desdobramentos desta expansão, ainda em curso, carecem de serem explorados com vistas ao aprimoramento dos processos de planejamento de suas instituições.

Ademais, o PDI foi concebido como instrumento oficial de planejamento para as Instituições de Ensino Superior (IES). Também adotado como instrumento de gestão pelos Institutos Federais. Instituído pelo Decreto No 5.773/2006, o PDI é o documento balizador do planejamento. Nele estão definidos a missão e as estratégias da instituição com a finalidade de atingir seus objetivos e metas para um período de cinco anos.

Outrossim, a escolha do tema se fundamenta na necessidade de acompanhar a falta de avaliação da efetividade dos documentos que norteiam o planejamento nos Institutos Federais, uma vez que são instituições relativamente recentes, ofertam educação pública abrangendo todo seu itinerário formativo, e carecem de um instrumento de planejamento, acompanhamento e avaliação que contemple toda a diversidade de sua atuação, não se encerrando apenas nas dimensões avaliadas pela da Lei do SINAES, que foi instituída para avaliar apenas as IES.

Assim sendo, a presente pesquisa, ao confrontar as legislações pertinentes à Educação Profissional com as relacionadas à Educação Superior, pretende identificar pontos que ainda precisam ser abordados no planejamento institucional dos Institutos Federais com o propósito de propor um marco legal estável para ser adotado pelos Institutos Federais. 


\section{REFERENCIAL TEÓRICO}

\subsection{PLANEJAMENTO ESTRATÉGICO}

Segundo Meyer Jr. (1988), o Planejamento Estratégico pode ser definido como um processo continuado e adaptativo, por meio do qual uma organização define e redefine sua missão, seus objetivos e suas metas, seleciona as estratégias e meios para atingi-las em um determinado período de tempo, por meio de constante interação com o ambiente externo.

Apesar de semelhantes, as instituições públicas e privadas se diferenciam. Enquanto uma goza de uma certa liberdade no tocante à legislação e são constituídas para atender interesses privados, as públicas estão estritamente subordinadas às leis e, via de regra, têm por finalidade atender às necessidades da sociedade.

De igual maneira, o planejamento estratégico nas instituições públicas e privadas possui similaridades, todavia, em alguns aspectos, são distintos. Enquanto nas instituições públicas o planejamento estratégico se dá por meio de normativos legais, em especial, no caso dos Institutos Federais, pelo do próprio PDI. Nas instituições privadas, o planejamento estratégico é estabelecido pelos seus dirigentes. Assim sendo, para melhor compreender cada uma destas vertentes, abordaremos o planejamento estratégico nas instituições públicas e privadas em separado nas subseções a seguir.

\subsubsection{Abordagem na iniciativa privada}

Destaca-se que, inicialmente, o planejamento estratégico estava limitado à análise dos pontos fortes e fracos de uma organização, que, logo depois, se ampliou, apresentando preocupações com o planejamento e a administração de eventuais mudanças no ambiente organizacional (BERTERO, 1995).

Os autores Fischmann e Almeida (2009), vão além afirmando que o planejamento estratégico pode ser definido como uma técnica administrativa que, a partir da análise do ambiente de uma organização, identifica suas oportunidades e ameaças, seus pontos fortes e 
fracos, e, em sintonia com sua missão, cria uma direção a ser seguida em busca de seus objetivos.

Para Gelbcke et al. (2006) e Bateman (2006), o planejamento estratégico é um conjunto de procedimentos para tomada de decisões que permite definir missão, valores e objetivos da instituição, como um marco inicial do processo de mudança organizacional de longo prazo. Nesta mesma perspectiva, Kwasnicka (2007, p. 207) afirma que "ao trabalhar com planejamento estratégico, a empresa caminha sem gastar muito tempo e recursos imediatos para a solução de seus problemas”.

Do mesmo modo, Cunha (1995) afirma que o planejamento estratégico consiste em um processo de percepção ambiental, tanto externa quanto interna, e de uma análise sistemática dos pontos fortes e fracos da organização, assim como das oportunidades e ameaças do meio ambiente com a finalidade de estabelecer objetivos, estratégias e ações que possibilitem o aumento de sua performance.

De acordo com Almeida (2009), o planejamento estratégico é uma técnica administrativa que procura ordenar as ideias das pessoas, de forma que se crie uma visão do caminho que se deve seguir (estratégia).

Sob o mesmo ponto de vista, Oliveira $(2008$, p.17) nos traz ainda em seu parecer, que

o planejamento estratégico é o processo administrativo que proporciona sustentação metodológica para se estabelecer a melhor direção a ser seguida pela empresa, visando ao otimizado grau de interação com os fatores externos - não controláveis - e atuando de forma inovadora e diferenciada.

Desta forma, Rezende (2008, p.18) inova, afirmando que "o planejamento estratégico da organização é um processo dinâmico, sistêmico, coletivo, participativo e contínuo para determinação dos objetivos, estratégias e ações da organização”.

De outra forma, Arguin (1988) acredita que o modelo de planejamento estratégico ideal é aquele que através de determinadas compreensões da instituição, seja possível identificar os ambientes institucionais de relacionamentos e principalmente a integração entre eles. 
2.1.2 Abordagem nas instituições públicas em geral e nas de ensino

De forma admirável, Cunha (1995) afirma que as instituições públicas, por serem criadas e sustentadas pelo poder público, geralmente têm a sua sobrevivência garantida e, portanto, não desenvolvem grandes preocupações com ameaças e oportunidades. Ao mesmo tempo, encontram grandes dificuldades para definir e operacionalizar os seus objetivos, assim como carecem de habilidade gerencial para estabelecer mudanças rápidas.

Por outro lado, Kaufman (1991) ressalta que, apesar das diferenças fundamentais existentes entre as empresas privadas e as instituições públicas, as características essenciais de organização de ambas tornam o conceito de planejamento estratégico aplicável às IES, pois ele diz respeito à necessidade de estabelecer sua missão, seu papel e os seus objetivos.

Percebe-se atualmente uma unanimidade quanto à importância do planejamento nas IES, visto que não se concebe mais o desenvolvimento de uma instituição social contemporânea sem um esforço planejado, pois, como Meyer Jr. (1991) afirma que os estudos de caso têm mostrado que as instituições universitárias cada vez mais reconhecem a necessidade e as vantagens de se planejar e administrar estrategicamente.

Nesta perspectiva, Colombo (2004), avalia que o planejamento estratégico é uma importante ferramenta de gestão que auxilia, consideravelmente, o administrador educacional em seus processos decisórios na busca de resultados mais efetivos e competitivos para a instituição de ensino.

Dessa maneira, entende-se que o planejamento estratégico se baseia em definir os objetivos e as metas da organização, e onde direcionar seus recursos para atingi-las. O planejamento possibilita para a organização a otimização de tempo, recursos, custos e benefícios no alcance dos objetivos (ATHANÁZIO, 2010).

Em suma, Costábile (2007), nos traz que o processo do planejamento estratégico consiste em definir os objetivos que devem ser alcançados, as atividades que devem ser 
executadas e os recursos que devem ser utilizados, a fim de que todos os propósitos de uma instituição sejam realmente alcançados.

\subsection{A REDE FEDERAL DE EDUCAÇÃO PROFISSIONAL}

\subsubsection{Evolução da Educação Profissional e Tecnológica}

A centenária Rede Federal, surgiu por meio do Decreto $N^{\circ} 7.566$, de 23 de setembro de 1909, que cria nas capitais dos Estados da República Brasileira, 19 Escolas de Aprendizes e Artífices, para o ensino profissional primário e gratuito. (BRASIL, 1909).

Inicialmente vinculadas ao Ministério da Agricultura, Indústria e Comércio, foi somente em 1930 que o então presidente Getúlio Vargas, por meio do Decreto № 19.444 , de 01 de dezembro de 1930, criou o Ministério da Educação e Saúde Pública, e vinculou as escolas de Artífices e Aprendizes à Superintendência do Ensino Profissional. (BRASIL, 1930).

Por meio da Lei $\mathrm{N}^{\circ}$ 378, de 13 de janeiro de 1937, o governo Vargas deu uma nova organização ao Ministério da Educação e Saúde Pública, dentre outros ajustes, transformou as Escolas de Aprendizes e Artífices em Liceus Profissionais, destinando-os ao ensino profissional em todos os ramos e graus. (BRASIL, 1937).

Em 1942, a "Reforma Capanema", por meio do Decreto-lei No 4.073, de 30 de janeiro de 1942, passou a considerar o ensino profissional como ensino médio. Estabeleceu que o ingresso dos alunos nas escolas industriais fosse realizado por meio de exames de admissão e que seus cursos fossem divididos nos dois ciclos do ensino médio existentes à época. (BRASIL, 1942a).

No mesmo ano, o Decreto-lei $\mathrm{N}^{\mathrm{o}} 4.127 / 1942$, estabeleceu as bases de organização da Rede Federal, reformulou os Liceus Profissionais denominando-os de Escolas Industriais e Técnicas. O ensino industrial e técnico passou a ser vinculado ao ensino formal e permitiu aos estudantes formados nos cursos técnicos ingressarem diretamente no ensino superior. (BRASIL, 1942b). 
No governo de Juscelino Kubitschek (1956-1961), o Estado aprofunda sua relação com a economia. No seu plano de metas, além de prever fortes investimentos em infraestrutura, pela primeira vez, reservou 3,40\% do orçamento federal para educação, com o objetivo de formar profissionais orientados para as metas de desenvolvimento do país.

Neste período, por intermédio da Lei № 3.552, de 16 de fevereiro de 1959, as Escolas Industriais e Técnicas são transformadas em autarquias e passam a se chamar de Escolas Técnicas Federais (ETF), com autonomia administrativa, didática, técnica e financeira, intensificando a formação de técnicos, mão de obra necessária para o processo de industrialização no país. (BRASIL, 1959).

Com a intenção de formar engenheiros de operação e tecnólogos, o presidente Geisel, sancionou a Lei No 6.545/1978, transformando as ETFs de Minas Gerais, Paraná e Rio de Janeiro em CEFETs, passando a ofertar além de cursos técnicos, cursos superiores e de pósgraduação. (BRASIL, 1978).

Passado o regime militar, já no período democrático, o então Presidente Itamar Franco, sancionou a Lei $\mathrm{N}^{\mathrm{o}} 8.948$, de 8 de novembro de 1994, e com ela deu continuidade ao processo de "CEFETização" das instituições federais de educação profissional, transformando gradativamente as Escolas Técnicas e Agrotécnicas Federais em CEFETs. (BRASIL, 1994a).

Em 1996, o então presidente Fernando Henrique Cardoso sancionou a segunda LDB. Nela, a Educação Profissional passou a ser tratada em um capítulo específico, separado da educação básica. Além disso, definiu o sistema de certificação profissional, permitindo o reconhecimento dos saberes e competências adquiridos fora do âmbito educacional. (BRASIL, 1996).

No ano seguinte, o Decreto No 2.208, de 17 de abril de 1997, regulamentou a Educação Profissional e estabeleceu o Programa de Expansão da Educação Profissional (PROEP), 
programa financiado pelo Banco Interamericano de Desenvolvimento (BID), voltado para a ampliação da oferta de educação profissional pela iniciativa privada. (BRASIL, 1997).

Conforme apresentado na Figura 1, no período de 1909 a 1998, a Rede Federal passou por inúmeras mudanças. Neste período foram criadas 140 unidades de ensino, todavia este crescimento foi interrompido com a assinatura da Lei $\mathrm{N}^{\circ}$ 9.649/1998, ficando seu desenvolvimento estagnado até o ano de 2005.

Figura 1 - Principais mudanças na Rede Federal no período de 1909 a 1998

-Decreto № 7.566, que cria 19 Escolas de Aprendizes Artifices

•Decreto № 19.444, cria o Ministério da Educação e Saúde Pública

- Lei № 378, dá nova organização ao MEC e transforma as Escolas de Aprendizes e Artífices em Liceus Prifssionais

-Decreto-lei № 4.073 estabelece as bases do ensino profissional e o Decreto $\mathrm{N}$ 4.127 transforma os Liceus em Escolas Industriais e Técnicas

- Lei № 3.552, as escolas técnicas passam a se chamar de Escolas Técnicas Federais transformam-se em autarquias

- Lei № 6.545, transoforma as Escolas Técnicas existentes em CEFETs e passam a ofertar cursos de engenharia e pós-graduação

•Lei № 8.948, dá continuidade ao processo de "CEFETização" transformando as Escolas Técnicas em CEFETs

-A Lei № 9.394 passa a tratar a Educação profissioal em um capítulo específico, desvinculando-a da educação básica

- Decreto № 2.208, regulamenta a educação profissional e estabelece o PROEP

•Lei № 9.649, "proíbe" a ampliação da Rede Federal

Fonte: Elaborado pelo autor

A retomada do crescimento da Rede Federal se deu no primeiro mandato do expresidente Luiz Inácio Lula da Silva. A Lei No 11.195/2005, atribuiu novamente à União a oferta de educação profissional no país. Este ato marcou o início da expansão da Rede Federal com a criação de 64 novas unidades de ensino profissional no país. (BRASIL, 2005).

Em 2006, o Decreto $\mathrm{N}^{\mathrm{o}} 5.773 / 2006$, dispunha sobre o exercício das funções de regulação, supervisão e avaliação de IES e de cursos superiores de graduação e sequenciais no 
sistema federal de ensino. Em seu Art. 45, atribuiu à Secretaria de Educação Profissional e Tecnológica (SETEC) a supervisão dos cursos superiores de tecnologia. (BRASIL, 2006).

No ano de 2007, o MEC realizou a $1^{\text {a }}$ Conferência Nacional de Educação Profissional e Tecnológica. Neste ano, foi dado início à segunda fase de expansão da Rede Federal, com a criação de 150 novos campi na perspectiva de, até 2010, alcançar a marca de 354 unidades de ensino profissional, atendendo a todas as unidades da federação.

Na sequência, a Lei $N^{\circ} 11.892 / 2008$, instituiu a Rede Federal e criou os Institutos Federais. Sua principal característica foi a oferta de educação profissional em suas mais diversas modalidades. A Figura 2, apresenta a distribuição dos 564 campi em todo Território Nacional.

Figura 2 - Distribuição geográfica dos 564 campi dos Institutos Federais em 2016

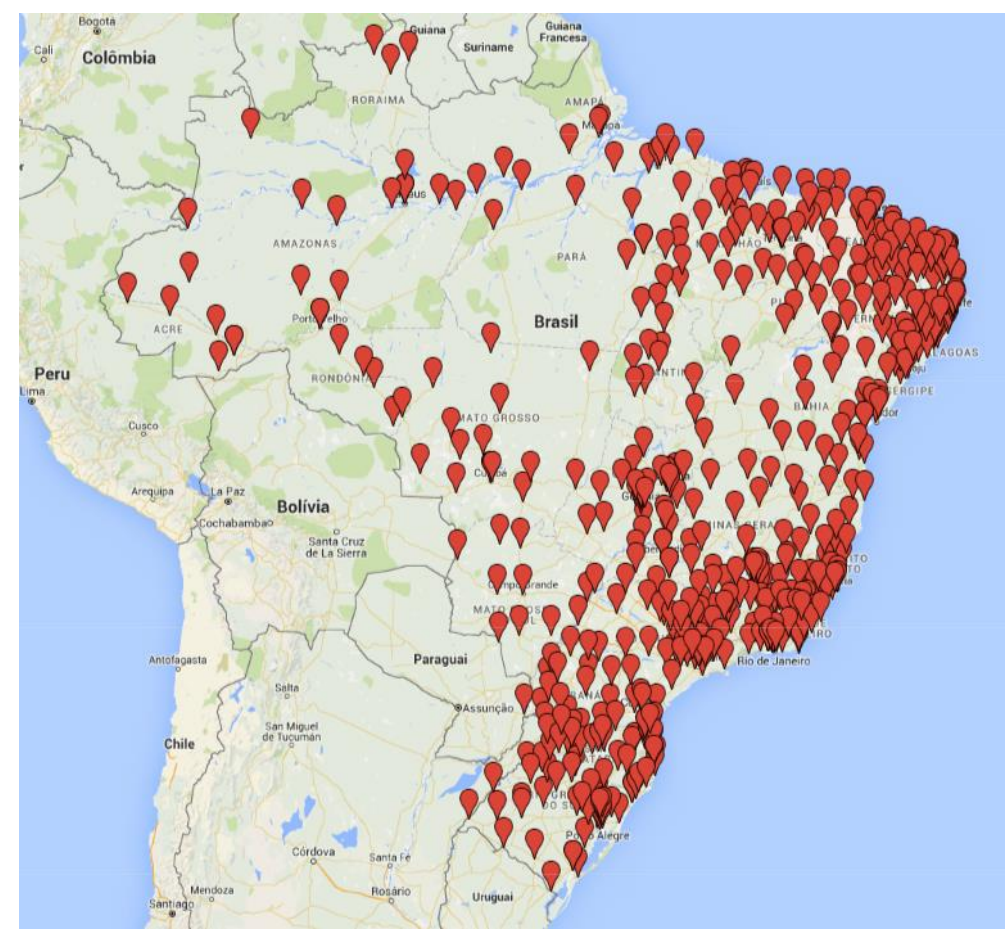

Fonte: Elaborado pelo autor

Em agosto de 2011, no primeiro mandato do governo Dilma Roussef, a presidenta anunciou a terceira fase de expansão da Rede Federal com 210 novas unidades, na expectativa de alcançar $10 \%$ dos municípios brasileiros. Nos últimos dez anos, a Rede Federal cresceu 176\%, atingindo, conforme Figura 3, um total 564 unidades no ano de 2016. 
Figura 3 - Quantidade de unidades da Rede Federal nos seus 107 anos de existência

\begin{tabular}{|c|c|c|c|c|}
\hline & & & & 564 \\
\hline & & & 354 & \\
\hline & 110 & 204 & & 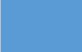 \\
\hline 19 & & & & \\
\hline 1909 & 1998 & 2005 & 2010 & 2016 \\
\hline
\end{tabular}

Fonte: Elaborado pelo autor

\subsubsection{O Instituto Federal de Brasília}

O IFB foi criado pela Lei $\mathrm{N}^{\mathrm{0}} 11.892$, de 29 de dezembro de 2008, durante a segunda fase de expansão da Rede Federal. A antiga Escola Agrotécnica Federal de Brasília foi incorporada à sua estrutura, transformando-se no Campus Planaltina. Além desse campus, foram criados os campi Brasília, Taguatinga, Samambaia e Gama. (BRASIL, 2008).

No ano de 2011, acompanhando a terceira fase de expansão da Rede Federal, foram criados mais cinco campi no IFB, atendendo às regiões administrativas de São Sebastião, Riacho Fundo, Ceilândia, Estrutural e Taguatinga Centro. Inicialmente ofertando cursos de curta duração à comunidade em espaços cedidos pelo governo do Distrito Federal (DF), hoje contam com estrutura própria e oferecem ensino profissional e superior em suas unidades.

Atualmente, das 10 unidades do IFB presentes no Distrito Federal, apenas o campus Taguatinga Centro se encontra em sede provisória. Concebido para atender ao Programa Mulheres Mil $^{1}$, em função da grande demanda por qualificação profissional, este campus acabou se firmando, e hoje oferta cursos de Formação Inicial e Continuada (FIC), cursos técnicos, licenciatura e pós-graduação. A Figura 4 apresenta a atual distribuição geográfica dos 10 campi do IFB no DF.

\footnotetext{
${ }^{1}$ O Programa Mulheres Mil é uma política de governo que busca promover cidadania e qualificação a mulheres situadas em áreas de vulnerabilidade social (CARVALHO, 2013).
} 
Figura 4 - Distribuição geográfica dos campi do IFB no DF

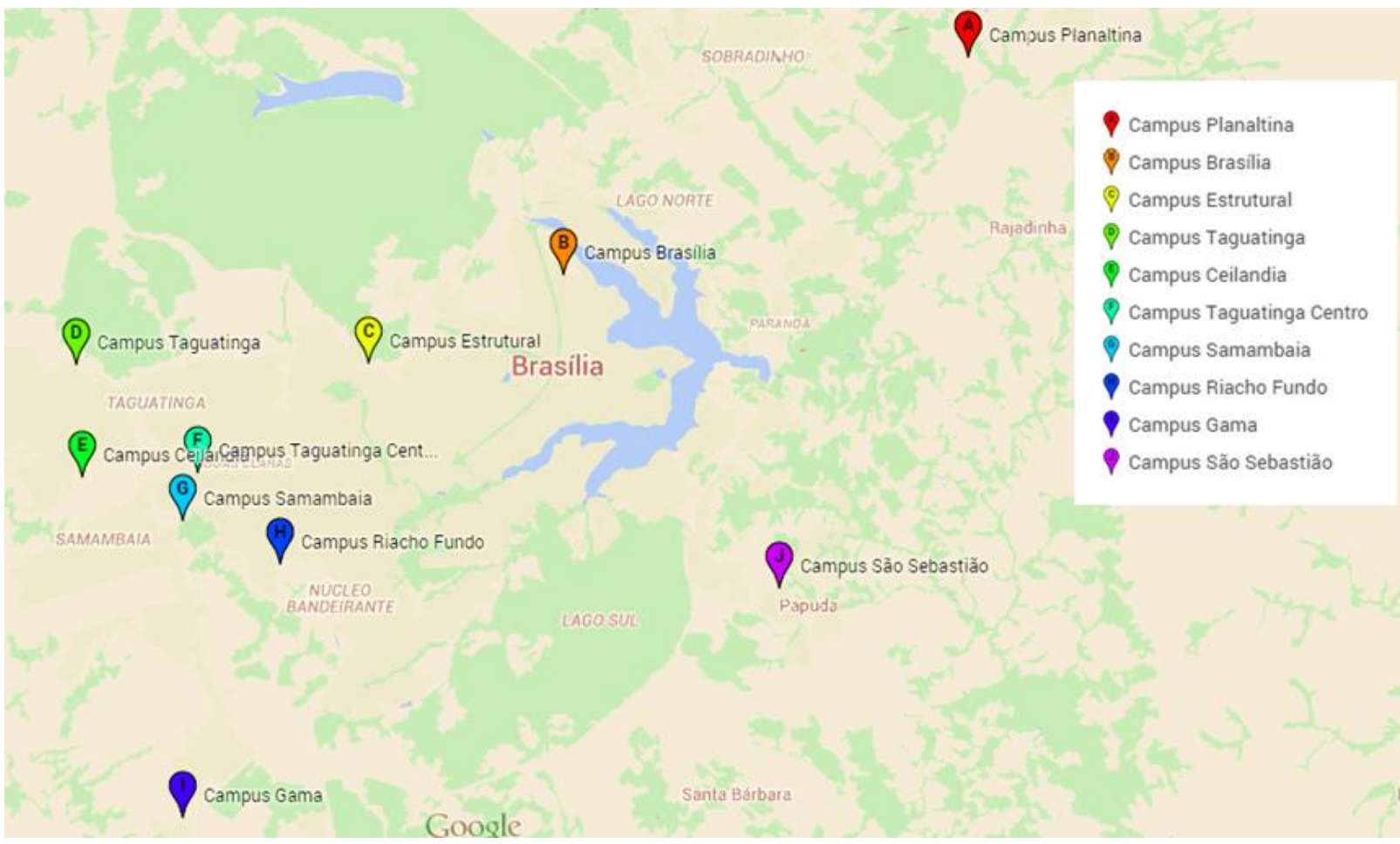

Fonte: Elaborado pelo autor

\subsection{A LEGISLAÇÃO DO PDI}

A elaboração do PDI bem como o funcionamento e oferta de educação profissional e tecnológica na Rede Federal são regulamentadas por vasta e dinâmica legislação, fruto do processo relativamente recente da democratização no Brasil.

Pontualmente, para melhor compreender o PDI, abordaremos as legislações pertinentes ao SINAES e ao PDI. Tal abordagem se faz necessária uma vez que esta pesquisa se propõe a estudar o PDI, um documento público e regulamentado, usado como ferramenta de gestão e acompanhamento plurianual tanto nas instituições que as elaboram quanto pelos órgãos públicos de controle.

\subsubsection{O Sistema Nacional de Avaliação da Educação Superior (SINAES)}

A regulação do Ensino Superior no país teve início por meio do primeiro instrumento de avaliação do SINAES, instituído pela Portaria No 300/2006 que aprovou Instrumento de Avaliação Externa de Instituições de Educação Superior (BRASIL, 2006a) e, um mês depois, 
a Portaria No 563/2006, aprovou o Instrumento de Avaliação de Cursos de Graduação (BRASIL, 2006b) que, doravante, foram utilizados na avaliação dos cursos de graduação.

No mesmo ano, o Decreto $\mathrm{N}^{\circ} 5.773 / 2006$, dispõe sobre o exercício das funções de regulação, supervisão e avaliação de IES e de cursos superiores de graduação e sequenciais no sistema federal de ensino (BRASIL, 2006c).

Desta forma, o sistema federal de ensino superior compreende as Instituições Federais de Educação Superior (IFES), as IES, criadas e mantidas pela iniciativa privada, e os órgãos federais de educação superior. A competência para a função de regulação, supervisão e avaliação serão exercidas pelo MEC, pelo Conselho Nacional de Educação (CNE), pelo Instituto Nacional de Estudos e Pesquisas Educacionais Anísio Teixeira (INEP), e pela Comissão Nacional de Avaliação da Educação Superior (CONAES) (BRASIL, 2006c).

Atualmente, na educação superior brasileira, a avaliação institucional é um dos pilares que estruturam uma das prioridades do Governo Federal. Parte constituinte das políticas das IES e do Estado que está embasada pela Lei No 10.861/2004. Esta Lei, em seu Art. $3^{\circ}$, define o PDI como um dos instrumentos obrigatórios de avaliação dos cursos das instituições ofertantes de educação superior (BRASIL, 2004).

Corroborando com o tema, Silva (2008) afirma que a gestão eficiente de uma IES é de grande complexidade. A criação de valor para alunos, professores, funcionários e sociedade está fundamentada no gerenciamento equilibrado dos ativos intangíveis (conhecimento, processos, sistemas e informação) e no planejamento e controle dos recursos financeiros que se traduzirão na prestação de serviços educacionais e na perenidade financeira do negócio.

Desta maneira, a lei que institui o SINAES foi regulamentada pelo Decreto $\mathrm{N}^{\mathrm{o}}$ 5.773/2006, que dispõe sobre o exercício das funções de regulação, supervisão e avaliação de IES e cursos superiores de graduação e sequenciais no sistema federal de ensino. Em seu Art. 12 determina que as IES, de acordo com sua organização e respectivas prerrogativas 
acadêmicas, serão credenciadas como faculdades, centros universitários e universidades (BRASIL, 2006c).

\subsubsection{O Plano de Desenvolvimento Institucional (PDI)}

O PDI é um documento que contém parte essencial do planejamento estratégico das IES. O PDI precisa considerar as políticas públicas, as necessidades institucionais e as demandas da comunidade. Sua composição mínima é estabelecida pelo Decreto N. ${ }^{\circ}$ 5.773/2006, que serve de guia para a elaboração do planejamento institucional. Esse documento orienta a avaliação institucional e de cursos, bem como, norteia os rumos que a IES precisa seguir.

Com o surgimento da Lei $\mathrm{N}^{\mathrm{o}} 10.861 / 2004$ e, consequentemente, da Portaria $\mathrm{N}^{\mathrm{o}}$ 300/2006, o PDI ganha status de referencial norteador da qualidade institucional, tornando-se instrumento fundamental na consolidação dos processos de avaliação institucional. Desse modo, confirma-se o exposto por Brasil (2004) que destaca a contribuição fundamental do documento na construção do projeto de avaliação da instituição, o qual deve se manter aderente às premissas propostas pelo PDI.

A Lei $N^{o} 10.861$ de 14 de abril de 2004, neste contexto, traz à luz uma significativa preocupação com a gestão institucional e o controle, possibilitando a utilização de frameworks ${ }^{2}$ no contexto da gestão dos projetos institucionais e coaduna-se com as necessidades do modelo acadêmico atual, onde os documentos institucionais são fundamentais.

Também conhecida como a Lei das Fundações de Apoio, a Lei № 8.958, de 20 de dezembro de 1994, que dispõe sobre as relações entre as instituições federais de ensino superior e de pesquisa científica e tecnológica e as fundações de apoio (BRASIL, 1994b), menciona, pela primeira vez na legislação brasileira, a necessidade da construção do PDI, o parágrafo $1^{\circ}$ do artigo $1^{\circ}$ traz:

\footnotetext{
2 Estrutura conceitual básica, arcabouço teórico que permite o manuseio homogêneo de diferentes objetos de negócio. Pode ser visto também como uma tática bem definida para manipular com destreza, ambientes organizacionais complexos. Um framework deve prover sugestões de solução para uma família de problemas semelhantes. (CELESTINO, 2012)
} 
"§ $1^{\circ}$ Para os fins do que dispõe esta Lei, entendem-se por desenvolvimento institucional os programas, projetos, atividades e operações especiais, inclusive de natureza infraestrutural, material e laboratorial, que levem à melhoria mensurável das condições das IFES e demais ICTs, para cumprimento eficiente e eficaz de sua missão, conforme descrita no plano de desenvolvimento institucional, vedada, em qualquer caso, a contratação de objetos genéricos, desvinculados de projetos específicos. (Incluído pela Lei $\mathrm{N}^{\mathrm{o}} 12.349$, de 2010)"

Em junho de 2002, o MEC, por meio do Sistema de Acompanhamento de Processos das Instituições de Ensino Superior (SAPIENS), publica documento destinado a servir de referência para a construção do PDI, respondendo às dúvidas e os questionamentos das IES.

Desta forma, o PDI consiste em um documento em que se definem a missão da instituição de ensino superior e as estratégias para atingir suas metas e objetivos. Abrangendo um período de 5 anos, deverá contemplar o cronograma e a metodologia de implementação dos objetivos, metas e ações do Plano da IES, observando a coerência e a articulação entre as diversas ações, a manutenção de padrões de qualidade e, quando pertinente, o orçamento. Deverá apresentar, ainda, um quadro-resumo contendo a relação dos principais indicadores de desempenho, que possibilite comparar, para cada um, a situação atual e futura, ou seja, após a vigência do PDI.

O PDI deve estar intimamente articulado com a prática e os resultados da avaliação institucional, realizada tanto como procedimento auto avaliativo, quanto procedimento externo. Quando se tratar de instituição já credenciada e/ou em funcionamento, os resultados dessas avaliações devem balizar as ações para sanar deficiências que tenham sido identificadas. Se a IES tiver apresentado PDI quando do credenciamento, o documento institucional deverá incluir, também, uma comparação entre os indicadores de desempenho constantes da proposta inicial e uma avaliação considerando-se a situação atual.

Apesar de obrigatório, o MEC permitiu que a construção do PDI fosse livre, garantindo às instituições o exercício de suas criatividades e liberdades no processo de sua elaboração. 
Entretanto, 10 dimensões $^{3}$ devem estar presentes no documento, por serem tomados como referenciais das análises subsequentes a serem realizadas pelo MEC, e que contempla os requisitos mínimos estabelecidos no decreto presidencial, sendo:

1 - Perfil institucional;

2 - Projeto Pedagógico Institucional - PPI;

3 - Cronograma de implantação e desenvolvimento da instituição e dos cursos (presencial e à distância);

4 - Perfil do corpo docente;

5 - Organização administrativa da IES;

6 - Políticas de atendimento aos discentes;

7 - Infraestrutura;

8 - Avaliação e acompanhamento do desenvolvimento institucional;

9 - Aspectos financeiros e orçamentários; e

10 - Anexos, que deve conter o regimento ou estatuto da IES. (Ministério da Educação, 2007).

Passados 10 anos da promulgação da Lei dos SINAES, diante da necessidade de atualização dos instrumentos de Avaliação Institucional Externa, o MEC, por meio da Portaria № 92, de 31 de janeiro de 2014, aprovou os indicadores do novo Instrumento de Avaliação Institucional Externa para os atos de credenciamento, recredenciamento e transformação de organização acadêmica, modalidade presencial, do SINAES. Em linhas gerais o documento reorganiza a avaliação institucional agrupando-a em cinco eixos, contemplando nestes, as 10 dimensões referenciadas no marco legal do SINAES. O agrupamento das dimensões em eixos tem a finalidade de facilitar o diálogo entre as atividades que devem ser articuladas no momento da avaliação da IES. A Tabela 1 apresenta esta reorganização de forma mais didática.

\footnotetext{
${ }^{3}$ Dimensões são agrupamentos de grandes traços ou características referentes aos aspectos institucionais sobre os quais se emite juízo de valor e que, em seu conjunto, expressam a totalidade da instituição. (INEP, 2005).
} 
Tabela 1 - Distribuição das 10 dimensões da Lei do SINAES nos cinco eixos de avaliação

\begin{tabular}{|c|c|c|c|c|}
\hline $\begin{array}{c}\text { Eixo 1: } \\
\text { planejamento e } \\
\text { avaliação } \\
\text { institucional }\end{array}$ & $\begin{array}{c}\text { Eixo 2: } \\
\text { desenvolvimento } \\
\text { institucional }\end{array}$ & $\begin{array}{c}\text { Eixo 3: } \\
\text { políticas acadêmicas }\end{array}$ & $\begin{array}{c}\text { Eixo 4: } \\
\text { políticas de gestão }\end{array}$ & $\begin{array}{c}\text { Eixo 5: } \\
\text { infraestrutura física }\end{array}$ \\
\hline $\begin{array}{l}\text { Considera as } \\
\text { dimensões: }\end{array}$ & $\begin{array}{l}\text { Contempla as } \\
\text { dimensões: }\end{array}$ & $\begin{array}{l}\text { Abrange as } \\
\text { dimensões: }\end{array}$ & $\begin{array}{l}\text { Compreende as } \\
\text { dimensões: }\end{array}$ & Contempla: \\
\hline $\begin{array}{l}\text { (8) planejamento e } \\
\text { avaliação; }\end{array}$ & $\begin{array}{l}\text { (1) missão e PDI } \\
\text { (3) responsabilidade }\end{array}$ & $\begin{array}{l}\text { (2) políticas para o } \\
\text { ensino, pesquisa e } \\
\text { extensão; }\end{array}$ & $\begin{array}{l}\text { (5) políticas de } \\
\text { pessoal; }\end{array}$ & $\begin{array}{l}\text { (7) infraestrutura } \\
\text { física }\end{array}$ \\
\hline $\begin{array}{l}\text { Relato institucional } \\
\text { descrevendo os } \\
\text { principais elementos }\end{array}$ & social & $\begin{array}{l}\text { (4) comunicação com } \\
\text { a sociedade; }\end{array}$ & $\begin{array}{l}\text { (6) organização e } \\
\text { gestão da instituição; }\end{array}$ & \\
\hline $\begin{array}{l}\text { do processo interno e } \\
\text { externo de avaliação } \\
\text { em relação ao PDI; }\end{array}$ & & $\begin{array}{l}\text { (9) políticas de } \\
\text { atendimento aos } \\
\text { discentes. }\end{array}$ & $\begin{array}{l}\text { (10) sustentabilidade } \\
\text { financeira. }\end{array}$ & \\
\hline $\begin{array}{l}\text { inclui os relatórios da } \\
\text { Comissão Própria de } \\
\text { Avaliação (CPA), do } \\
\text { período que constitui } \\
\text { o objeto da avaliação. }\end{array}$ & & & & \\
\hline
\end{tabular}

\section{METODOLOGIA DE PESQUISA}

Do ponto de vista de sua natureza, a presente pesquisa é aplicada, uma vez que, segundo Vilaça (2010), tem como motivação a produção de conhecimento para aplicação prática de seus resultados, na perspectiva de solucionar um problema real.

Do ponto de vista da abordagem do problema, a pesquisa é identificada como qualitativa, uma vez que há uma relação dinâmica entre o mundo real e o indivíduo, ou seja, um tipo de conhecimento que não pode ser traduzido em números. Sobre esta abordagem, Triviños (1987) avalia que há uma relação dinâmica entre o mundo real e o sujeito, e que a interpretação dos fenômenos e a atribuição de significados são básicos no processo de pesquisa qualitativa.

No que tange seus objetivos, a pesquisa é classificada como exploratória pois, tem por finalidade, adquirir maior conhecimento sobre o problema com o objetivo de torná-lo explícito ou construir hipóteses. De acordo com Piovesan e Temporini (1995) a pesquisa exploratória tem por objetivo conhecer a variável de estudo tal como se apresenta, seu significado e o contexto onde ela se insere. 
No que compete aos procedimentos técnicos, a pesquisa é caracterizada em três aspectos: (i) exploratória, em parte, pois é elaborada a partir de material já publicado. Segundo Gil (2008), pode-se dizer que estas pesquisas têm como objetivo principal o aprimoramento de ideias ou a descoberta de intuições; (ii) documental, uma vez que se utiliza de material que ainda não recebeu tratamento analítico; e (iii) pesquisa-ação, pois é concebida e realizada em estreita associação com uma ação ou com a resolução de um problema coletivo.

De acordo com Thiollent (1985, p. 14), a pesquisa-ação pode ser definida como:

"...um tipo de pesquisa com base empírica que é concebida e realizada em estreita associação com uma ação ou com a resolução de um problema coletivo e no qual os pesquisadores e participantes representativos da situação ou do problema estão envolvidos de modo cooperativo ou participativo."

\subsection{COLETA E ANÁLISE DOS DADOS}

\subsubsection{Análise do cumprimento das metas do PDI 2009/2013 do IFB}

A análise do cumprimento das metas estabelecidas no PDI foi realizada por meio de pesquisa documental. Foram considerados os documentos PDI IFB 2009/2013 (Doc 1) os Planejamentos Institucionais do IFB dos anos de 2009, 2010, 2011, 2012 e 2013 (Doc 2; Doc 3; Doc 4; Doc 5; Doc 6), os Relatórios de Gestão do IFB dos anos de 2009, 2010, 2011, 2012 e 2013 (Doc 7; Doc 8; Doc 9; Doc 10; Doc 11) e o Termo de Acordo de Metas (TAM) firmado entre o MEC e o IFB (Doc 12), estes constam no APÊNDICE A. Além disso, foi considerada a legislação pertinente à Educação Profissional vigente no período da análise desta pesquisa.

Conforme consta no documento analisado, para o sucesso de sua missão, a comissão de elaboração do PDI 2009/2013 do IFB definiu 12 objetivos gerais que se desdobraram em 152 metas previstas para serem executadas no período de cinco anos. Metas essas que ficaram a cargo da Pró-reitoria de Ensino (PREN), Pró-reitoria de Pesquisa e Inovação (PRPI), Próreitoria de Extensão (PREX), Pró-reitoria de Administração (PRAD) e pela Pró-reitoria de Desenvolvimento Institucional (PRDI), únicas estruturas administrativas existentes no momento da concepção do documento. 
O acompanhamento do cumprimento das metas foi realizado por meio do confronto das informações constantes no PDI IFB 2009/2013, nos documentos que versam sobre o Planejamento Institucional (PI) para o período de 2009 a 2013 e nos Relatórios de Gestão pertinentes ao mesmo período.

Para analisar a evolução do cumprimento deste planejamento foi realizado uma criteriosa análise documental no PDI, relacionando suas informações com as informações constantes nos Relatórios de Gestão relativos ao mesmo período, com vistas a identificar quais as metas que foram cumpridas, quais as que não foram cumpridas e quais as justificativas para estas alterações, assim, compreendendo melhor o planejamento da instituição e contribuindo com a melhoria constante do processo de planejamento do IFB.

Primeiramente foram elencadas as metas programadas no PDI 2009/2013 do IFB. Em seguida, foi verificado se as metas programadas no PDI constavam no PI de cada ano. Por fim, por meio dos Relatórios de Gestão, pôde-se constatar se cada meta proposta foi efetivamente cumprida, elencando o seu status bem como identificando a justificativa para o não cumprimento ou o surgimento e andamento de novas metas.

\subsubsection{Identificação dos gargalos encontrados no uso do PDI nos Institutos Federais}

Os gargalos do PDI foram identificados por meio da obtenção da percepção dos gestores da Rede Federal. Para tanto, foi aplicado para os gestores por meio de formulário eletrônico encaminhado por e-mail, um questionário semiestruturado dividido em duas partes.

A primeira parte do questionário foi distribuída em quatro perguntas abertas e teve como intenção analisar os gargalos do PDI relacionados aos aspectos sociais e culturais, aspectos políticos e institucionais, aspectos legais e administrativos e os aspectos pedagógicos e metodológicos.

A segunda parte do questionário foi elaborada com questões fechadas, elas têm por objetivo avaliar se algumas características da amostra poderiam afetar a percepção dos 
respondentes em relação ao PDI, tais como: o grau de escolaridade, a frequência na utilização do PDI pelo servidor, além da identificação de se a sua área de formação acadêmica é a mesma área de atuação na instituição. O Quadro 1 traz em detalhes o questionário aplicado aos gestores da Rede Federal.

Quadro 1 - Perguntas do questionário aplicado aos gestores da Rede Federal

I. GARGALOS NO PDI (Informe nos campos abaixo, na forma de tópicos, quais aspectos relacionados que, na sua percepção sobre cada item apresentado, possam ser possíveis gargalos e/ou possibilidades de melhoria necessários para aprimorar uso do PDI como uma ferramenta de gestão.)

1. Aspectos sociais e culturais (Compreende-se como aspectos sociais aqueles relacionados à desigualdade social, etnia, gênero, geração, orientação sexual, credo, dentre outros. Entende-se por aspectos culturais aqueles que estão relacionados às práticas, símbolos, valores, comportamentos, hábitos, crenças, princípios, dentre outros.)

2. Aspectos políticos e institucionais (Compreende-se como aspectos políticos aqueles relacionados às relações interinstitucionais, governamentais, parcerias, bem como às práticas democráticas, transparência, publicidade, dentre outros. Compreende-se aspectos institucionais como tradição, missão, visão, valores, objetivos, finalidade da instituição, dentre outros.)

3. Aspectos legais e administrativos (Compreende-se como aspectos legais aqueles que fazem referência às normas, regulamentos, regimentos, à legislação vigente e correlatos. Compreende-se por aspectos administrativos aqueles que fazem referência ao planejamento, às finanças, ao orçamento, à estrutura organizacional, ao planejamento, aos recursos humanos, dentre outros.)

4. Aspectos pedagógicos e metodológicos (Compreende-se como aspectos pedagógicos aqueles relacionados ao tipo de ensino, avaliação, conteúdo, estruturação dos cursos, projeto político institucional, dentre outros. Compreende-se como aspectos metodológicos aqueles relacionados à definição de espaço e tempo do ensino, métodos de aprendizagem, formação e qualificação dos educadores, dentre outros).

\section{CARACTERÍSTICAS DA AMOSTRA}

5. Com que frequência você faz uso do PDI? (Responda assinalando uma das opções abaixo)

( ) Nunca utilizo ( ) Anualmente ( ) Semestralmente ( ) Bimestralmente
( ) Mensalmente ( ) Quinzenalmente ( ) Semanalmente ( ) Diariamente

6. Qual o seu nível de escolaridade atual? (Considere para esta resposta seu maior nível formação concluída no presente momento)

( ) Fundamental ( ) Médio ( ) Superior ( ) Pós-graduação (Lato senso)

( ) Mestrado ( ) Doutorado ( ) Pós-doutorado

7. Nas suas atividades, você atua na sua área de formação?

( ) Sim ( ) Não

Fonte: Elaborado pelo autor

A aplicação do questionário ocorreu entre o período de dezembro de 2015 a fevereiro de 2016. O questionário foi encaminhado por e-mail para o endereço eletrônico de 7.408 gestores da Rede Federal incluídos os do IFB, todos servidores públicos que atuam em cargos de direção 
e, portanto, lidam direta ou indiretamente com o planejamento nas instituições em que trabalham. A identificação dos servidores que atuam em cargos de gestão foi obtida a partir de informações públicas disponíveis no portal da transparência. (BRASIL, 2014).

A amostra alcançada contou com 97 questionários inteiramente respondidos, representando gestores de 21 instituições distintas do país. Alguns fatores que dificultaram a ampliação da amostra foram: a falta de padronização dos e-mails na Rede Federal; o bloqueio de mala direta por ferramentas AntiSpam ${ }^{4}$ nos servidores de correio eletrônico de algumas instituições; a característica facultativa de preenchimento do questionário; a aplicação do questionário coincidir com o período de recesso e de férias dos gestores.

Para a análise dos dados, em especial, as informações provenientes das perguntas abertas do questionário, foi utilizada a técnica de Análise de Conteúdo. Para Bardin (2011), a análise de conteúdo pode ser compreendida como:

um conjunto de técnicas de análise das comunicações visando a obter, por procedimentos sistemáticos e objetivos de descrição de conteúdo das mensagens, indicadores (quantitativos ou não) que permitam a inferência de conhecimentos relativos às condições de produção/recepção (variáveis inferidas) destas mensagens (BARDIN, 2011, p. 45).

Como balizador, optou-se por adotar as etapas da técnica proposta por Bardin (2011) que são: 1) pré-análise, 2) exploração do material e 3) interpretação dos resultados.

Assim sendo, na pré-análise e exploração do material, foi feita uma leitura flutuante das respostas e identificado as categorias em que elas se enquadravam, adotando como categorias as 10 dimensões de avaliação proposta pelo SINAES: 1) missão e PDI; 2) políticas para o ensino, pesquisa e extensão; 3) responsabilidade social; 4) comunicação com a sociedade; 5) políticas de pessoal; 6) organização e gestão da instituição; 7) infraestrutura física; 8) planejamento e avaliação; 9) políticas de atendimento aos discentes; 10) sustentabilidade financeira.

\footnotetext{
${ }^{4}$ AntiSpam é uma ferramenta usualmente empregada pelos provedores, que pretende ajudar o usuário a evitar o recebimento de mensagens indesejadas, tais como propagandas de produtos ou sites e "correntes" e abaixoassinados, entre outros. (NUNES, 2004).
} 
A fase de interpretação dos resultados calculou a frequência das respostas dentro de cada categoria proposta pelo SINAES, permitindo verificar qual categoria apresentou o maior número de críticas ou sugestões, bem como, apresentou-se o conteúdo das respostas mais representativas.

Por fim, utilizou-se de análise gráfica e estatística descritiva para as perguntas fechadas referentes a característica da amostra. Foi possível verificar a familiaridade dos respondentes no que se refere ao uso do PDI no dia a dia do seu trabalho nas instituições. Para tal foi averiguado sua frequência no uso do documento, o grau de escolaridade dos entrevistados bem como, se eles atuam ou não na sua área de formação.

\subsection{DELIMITAÇÃO DA PESQUISA}

A pesquisa limitou-se a analisar as metas que compõem os objetivos gerais estabelecidos no PDI 2009/2013 do IFB. O recorte se fez necessário em virtude do PDI ser o documento oficial balizador do planejamento da instituição e, por ter sido o PDI o primeiro instrumento de gestão inteiramente executado pelo IFB.

Tal delimitação também se fez necessária em virtude de ter sido constatado, no confronto das informações constantes no PDI em questão com as declaradas nos planejamentos anuais e nos relatórios de gestão do período de 2009 a 2013, metas não previstas no PDI 2009/2013 do IFB.

\section{RESULTADOS E DISCUSSÕES}

\subsection{ANALISANDO AS METAS DO PDI 2009/2013 DO IFB}

Conforme evidenciado no PDI 2009/2013 do IFB, 12 objetivos gerais foram definidos para serem trabalhados no período de cinco anos. A Tabela 2, apresenta a distribuição das metas necessárias para o alcance destes objetivos, estão dispostas de forma agrupada em seus respectivos objetivos gerais e distribuídas pelos anos de vigência do PDI. Uma vez que algumas 
destas metas se estendem por mais de um exercício, para sua alocação, levou-se em consideração o prazo final para sua conclusão.

Tabela 2 - Distribuição das metas estabelecidas no PDI 2009/2013 do IFB

\begin{tabular}{lccccccc}
\hline \multirow{2}{*}{\multicolumn{1}{c}{ Objetivos Gerais }} & \multicolumn{9}{c}{ Quantidade de metas por exercício } & $\begin{array}{c}\text { Total de metas } \\
\text { por objetivo } \\
\text { geral }\end{array}$ \\
\cline { 2 - 6 } & $\mathbf{2 0 0 9}$ & $\mathbf{2 0 1 0}$ & $\mathbf{2 0 1 1}$ & $\mathbf{2 0 1 2}$ & $\mathbf{2 0 1 3}$ & 17 \\
\hline 1. Ampliar a oferta de cursos técnicos & 11 & 5 & 1 & 0 & 0 & 11 \\
2. Implementar cursos superiores & 2 & 6 & 2 & 1 & 0 & 25 \\
3. Melhorar a qualidade do ensino & 6 & 15 & 2 & 1 & 1 & 8 \\
4. Implementar pós-graduação & 1 & 1 & 1 & 1 & 4 & 18 \\
5. Estruturar pesquisa tecnológica & 2 & 1 & 1 & 2 & 12 & 10 \\
6. Incrementar a integração com a comunidade & 4 & 3 & 2 & 0 & 1 & 14 \\
7.Ampliar estrutura física & 2 & 11 & 1 & 0 & 0 & 16 \\
8. Ampliar a gestão sistêmica & 3 & 10 & 1 & 0 & 2 & 11 \\
9. Promover melhorias na gestão pedagógica & 0 & 2 & 1 & 4 & 4 & 9 \\
10. Articular ensino, pesquisa e extensão & 1 & 1 & 0 & 0 & 7 & 11 \\
11. Implementar programa de qualidade de vida & 0 & 4 & 4 & 1 & 2 & 2 \\
12. Consolidar a marca IFB & \multicolumn{1}{c}{ Total por ano: } & $\mathbf{3 2}$ & $\mathbf{6 0}$ & $\mathbf{1 6}$ & $\mathbf{1 0}$ & $\mathbf{3 4}$ & $\mathbf{1 5 2}$ \\
\hline \multicolumn{1}{c}{} & & & & & & \\
\hline
\end{tabular}

Fonte: Elaborado pelo autor

Como se pode observar na Tabela 2, as metas constantes nos objetivos gerais 1, 2, 3 e 9, estão relacionadas diretamente às atividades de ensino e correspondem a 64 metas, ou $42 \%$ do total das metas previstas para serem executadas durante a vigência do PDI. Observa-se que estas metas, bem como as relacionadas à ampliação da infraestrutura física, foram priorizadas nos anos de 2009 e 2010, o que confirma a importância dada ao planejamento para a implantação do IFB no DF.

Em seguida, percebe-se no quantitativo de metas relacionadas ao objetivo geral 6 , a atuação mais intensa das atividades extensionistas nos três primeiros anos de vigência do IFB. Tais ações tinham por objetivo estabelecer parcerias com o setor produtivo para oferta de estágio aos estudantes, fechar acordos com embaixadas e consulados para promoção de intercâmbio de estudantes e professores, além de estabelecer parcerias com instituições filantrópicas e organizações sociais para realização de atividades de extensão do IFB. 
As metas referentes aos objetivos gerais 7, 8 e 11, que estão relacionadas diretamente às atividades administrativas como estrutura física, gestão sistêmica e gestão de pessoas, correspondem a 41 metas, ou $27 \%$ do total das metas previstas para serem executadas no PDI, o que demonstra a preocupação do planejamento institucional na implantação das unidades do IFB no DF bem como o controle dos processos e contratação de professores e técnicos para a oferta de ensino profissional.

Com importante relevância, as metas referentes aos objetivos gerais 4, 5 e 10 estão relacionadas às atividades de pesquisa e correspondem a 35 metas, ou 23\% do total das metas. Tal quantitativo demonstra o interesse da instituição no desenvolvimento da pós-graduação e nas atividades relacionadas a pesquisa. Todavia, boa parte destas metas foram estrategicamente alocadas para o final do planejamento, na expectativa da instituição já estar devidamente estruturada para o desenvolvimento das atividades de pesquisa.

Duas metas, que correspondem a menos de $2 \%$ do total, estão relacionadas ao objetivo geral 12, consolidar a marca do IFB. A primeira se propõe a "dar visibilidade à instituição nas instituições de ensino e de pesquisa públicas, comunitárias e privadas" e a segunda destina-se a "levar o nome da instituição a todos os organismos internacionais como a Organização das Nações Unidas para a Educação, a Ciência e a Cultura (UNESCO), o Programa das Nações Unidas para o Desenvolvimento (PNUD), entre outros, para estabelecer intercâmbios".

Vale ressaltar que, e apesar do "demonstrativo de capacidade e sustentabilidade financeira" ser um item obrigatório a constar no PDI, este encontra-se ausente no orçamento para o quinquênio em questão. Tal fato se deu em decorrência da instituição, ter sido recémcriada, ainda sem previsão financeira. A ausência desta previsão pode ter interferido na elaboração e execução do planejamento.

Para avaliar o alcance dos objetivos gerais estabelecidos no PDI 2009/2013 do IFB, analisou-se o cumprimento das metas, para tal, realizou-se o cruzamento das informações 
constantes no PDI 2009/2013 do IFB com as informações disponibilizadas nos Relatórios de Gestão do IFB dos exercícios de 2009, 2010, 2011, 2012 e 2013. O resultado da análise se encontra na Tabela 3.

Tabela 3 - Distribuição das metas alcançadas no PDI 2009/2013 do IFB

\begin{tabular}{lccc}
\hline \multicolumn{1}{c}{ Objetivos gerais } & $\begin{array}{c}\text { Metas } \\
\text { definidas por } \\
\text { objetivo geral }\end{array}$ & $\begin{array}{c}\text { Metas } \\
\text { alcançadas por } \\
\text { objetivo geral }\end{array}$ & $\begin{array}{c}\text { Percentual do total } \\
\text { dobjetivos gerais } \\
\text { alcançados }\end{array}$ \\
\hline 1. Ampliar a oferta de cursos técnicos & 17 & 13 & $77 \%$ \\
2. Implementar cursos superiores & 11 & 7 & $64 \%$ \\
3. Melhorar a qualidade do ensino & 25 & 23 & $92 \%$ \\
4. Implementar pós-graduação & 8 & 1 & $13 \%$ \\
5. Estruturar pesquisa tecnológica & 18 & 17 & $95 \%$ \\
6. Incrementar a integração com a comunidade & 10 & 7 & $70 \%$ \\
7.Ampliar estrutura física & 14 & 13 & $93 \%$ \\
8. Ampliar a gestão sistêmica & 16 & 9 & $57 \%$ \\
9. Promover melhorias na gestão pedagógica & 11 & 8 & $\mathbf{7 3 \%}$ \\
10. Articular ensino, pesquisa e extensão & 9 & 6 & $67 \%$ \\
11. Implementar programa qualidade de vida & 11 & 3 & $27 \%$ \\
12. Consolidar a marca IFB & 2 & 2 & $100 \%$ \\
\hline
\end{tabular}

Fonte: Elaborado pelo autor

Ao longo do período de vigência do PDI, com 100\% das metas cumpridas, pode-se constatar que o objetivo geral "consolidar a marca IFB" teve o melhor desempenho dentre os demais. Ações como dar visibilidade ao IFB nas instituições de ensino e de pesquisa, públicas, privadas, comunitárias e em organismos internacionais como UNESCO, OIT e PNUD, foram bastante exitosas.

Em seguida, com desempenho bastante satisfatório, o objetivo geral "estruturar a pesquisa tecnológica" alcançou 95\% de execução. Ações como a criação da revista do IFB, a promoção de eventos científicos regulares na instituição e a adoção de mecanismos internos de apoio a práticas de pesquisa, contribuíram para o alcance deste objetivo. Apenas a meta relacionada a consolidação do perfil dos pesquisadores findou como inconclusa.

Da mesma maneira, o objetivo geral "Ampliar a estrutura física", teve $93 \%$ de suas metas concluídas. Ações como o planejamento, licitação e construção das unidades do IFB 
foram consideradas satisfatórias. Também se destacou a aquisição de equipamentos de informática e o aumento no uso de sistemas na instituição. A única pendência identificada foi a paralização das obras no Campus Brasília em decorrência da falência da construtora.

Ainda com satisfatório alcance, o objetivo geral "melhorar a qualidade do ensino" concluiu 92\% de suas metas. A reformulação do Projeto Pedagógico Institucional, o planejamento e implementação de melhorias nos cursos técnicos, tecnológicos e licenciaturas da instituição e a implantação da avaliação institucional contribuíram para esta performance. Em contrapartida, o acompanhamento das ações relacionadas ao ensino não foram concluídos.

Com satisfatória efetivação, o objetivo geral "ampliar a oferta de cursos técnicos" executou $77 \%$ de suas metas. Dos 17 cursos técnicos previstos para serem planejados e efetivamente ofertados pela instituição no período de 2009 a 2013, apenas 3 cursos não foram iniciados. Tal fato se justificou pela falta de estrutura física e corpo docente específicos para a oferta destes cursos.

Com regular desempenho, o objetivo geral "promover melhorias na gestão pedagógica" executou $73 \%$ de suas metas. A elaboração das diretrizes de gestão das atividades de ensino, pesquisa e extensão, bem como a implantação do programa de capacitação docente e contribuíram para o alcance destas metas. Em contrapartida, a oferta de cursos na modalidade de Educação a Distância com recursos próprios não foi implementada.

Ainda com aceitável execução, o objetivo geral "incrementar a integração com a comunidade" conseguiu executar $70 \%$ das metas previstas. Ações como a melhoria da gestão participativa, o aumento do uso de sistemas informatizados e a normatização de processos de gestão contribuíram para este alcance. Em contrapartida, a oferta de estágio, o intercâmbio de estudantes e professores e as ações extensionistas ficaram prejudicadas.

$\mathrm{Na}$ análise realizada, também foi constatado que alguns objetivos gerais tiveram dificuldades em serem alcançados. O objetivo geral "articular ensino, pesquisa e extensão", 
cumpriu $67 \%$ de suas metas. A implantação do Conselho de Ensino, Pesquisa e Extensão (CEPE) e o estabelecimento de cooperação com outras instituições foram exitosas, todavia, a realização de aulas interdisciplinares e o desenvolvimento da iniciação científica não foram tão exitosos.

Com aceitável desempenho, o objetivo geral "implementar cursos superiores" conseguiu atingir $64 \%$ das metas previstas. Dos 13 cursos previstos para serem planejados e ofertados pela instituição no período de vigência do PDI, sete tiveram êxito na sua oferta, com destaque para a licenciatura em dança, primeiro curso desta categoria oferecido em toda a Rede Federal.

Com desempenho mediano, o objetivo geral "ampliar a gestão sistêmica", conseguiu cumprir 57\% de suas metas. A implantação de sistemas para controle dos processos administrativos e a capacitação de servidores para utilização destes sistemas foram bemsucedidos. Todavia, a estruturação da equipe administrativa da instituição, o repasse do orçamento e a execução financeira da reitoria para os campi não pode ser implementado.

Com desempenho baixo, o objetivo geral “ implementar o programa de qualidade de vida" teve apenas $27 \%$ de suas metas concluídas. Ações importantes como a implantação do programa de qualidade de vida para toda a comunidade não foram executados. Em função do campus Planaltina ser um campus agrícola, por receber estudantes residentes, apenas as metas relacionadas ao núcleo de saúde desta unidade foram parcialmente atendidas.

Com precário desempenho, o objetivo geral "implantar pós-graduação" executou apenas $13 \%$ de suas metas. A oferta da especialização em Educação de Jovens e Adultos (PROEJA) e a implantação do Conselho de Ensino, Pesquisa e Extensão (CEPE) foram ações bemsucedidas, em contrapartida, não foi possível ofertar outras especializações e mestrados previstos no planejamento institucional. 
Desta maneira, de acordo com a análise realizada, pôde-se observar um considerável esforço da gestão para o alcance dos objetivos gerais inicialmente definidos, também foi observado que foi dada especial atenção as metas relacionadas às atividades de ensino, como a oferta de cursos técnicos, tecnológicos, a estruturação da infraestrutura necessária para o desenvolvimento das atividades e o desenvolvimento da pesquisa tecnológica.

\subsection{IDENTIFICANDO GARGALOS NO PDI DOS INSTITUTOS FEDERAIS}

A Tabela 4 apresenta o total das opiniões distribuídas em cada aspecto. O aspecto político e administrativo recebeu 113 contribuições, o que corresponde a $45 \%$ do total das opiniões, o aspecto pedagógico e metodológico, com 49 opiniões, o aspecto legal e administrativo, com 45 respostas e o aspecto social e cultural com 44 respostas, que corresponde respectivamente a $20 \%, 18 \%$ e $17 \%$ do total das respostas.

Tabela 4 - Categorização das respostas distribuídas nos quatro aspectos analisados

\begin{tabular}{lcc}
\hline \multicolumn{1}{c}{ Aspectos analisados } & Quantidade & Percentual \\
\hline Social e cultural & 44 & $17 \%$ \\
Político e institucional & 113 & $45 \%$ \\
Legal e administrativo & 45 & $18 \%$ \\
Pedagógico e metodológico & 49 & $20 \%$ \\
\hline Total de respostas & $\mathbf{2 5 1}$ & $\mathbf{1 0 0 \%}$ \\
\hline
\end{tabular}

Fonte: Elaborado pelo autor

De imediato, pode-se perceber uma considerável diferença percentual entre as críticas e sugestões apresentadas para o aspecto político e institucional do PDI quando comparado aos demais aspectos. Com quase metade das respostas, foi possível identificar uma maior participação dos entrevistados na identificação de gargalos referentes a comunicação entre a instituição e a sociedade e na necessidade de revisar o planejamento institucional para que este venha refletir a realidade e as necessidades da comunidade. 


\subsubsection{Aspectos políticos e institucionais}

Compreende-se como aspectos políticos aqueles relacionados às relações interinstitucionais, governamentais, parcerias com outras instituições, bem como às práticas democráticas, transparência, publicidade, dentre outros. Já os institucionais representam os aspectos como tradição, missão, visão, valores, objetivos, finalidade da instituição, dentre outros.

A Figura 5, apresenta o agregado das respostas referentes aos aspectos políticos e institucionais. Dentre as três dimensões identificadas, destacou-se a dimensão "4: Comunicação com a Sociedade", com 67 opiniões, ou 59\% do total para este aspecto, seguido da dimensão “8: Planejamento avaliação", com 31 opiniões, ou 28\% do total das opiniões, e a dimensão "1: Missão e PDI", com 15 opiniões, ou 13\% do total das respostas.

Figura 5 - Percepções dos gestores sobre os aspectos políticos e institucionais

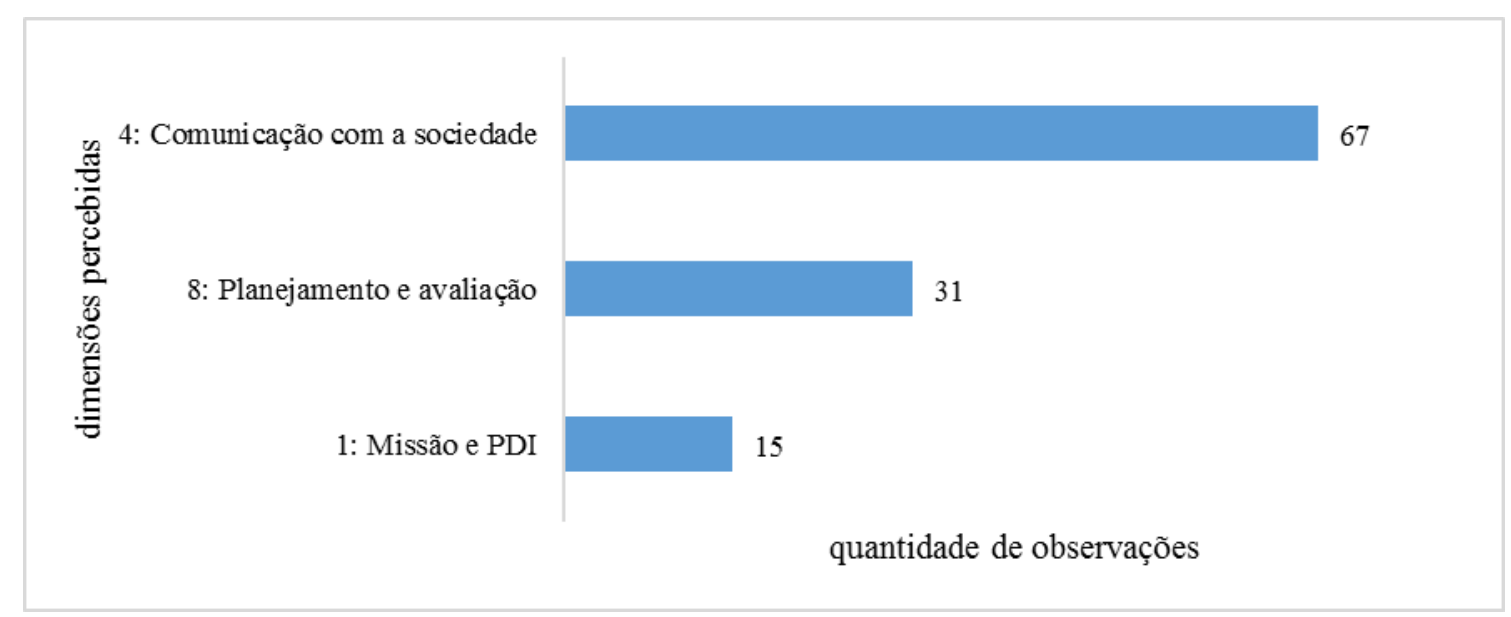

Fonte: Elaborado pelo autor

No que se refere à comunicação com a sociedade, importantes contribuições foram apresentadas na intenção de contornar a constatação sobre o desconhecimento da comunidade sobre a própria instituição. Dentre elas, a importância de esclarecer a comunidade sobre o que venha ser a missão, a visão, os valores, os objetivos e a finalidade da instituição. Também foi sugerido a divulgação do andamento das ações do PDI e o estabelecimento de políticas para 
promoção da transparência em toda instituição, com especial atenção ao orçamento e às finanças. Tais aspectos podem ser observados nas falas dos respondentes (R37, R56 e R85).

Por mais que a missão, visão e valores da instituição estejam escritas no PDI, falta uma ação efetiva da instituição no que se refere a sua disseminação (R37).

Transparência, divulgação e conscientização da missão, dos valores, objetivos e finalidade para qual o instituto foi criado (R56).

Não há transparência em relação as finanças e ao orçamento no instituto. Bem como o PDI não define políticas neste aspecto (R85).

Sobre esta dimensão também ficou latente a necessidade de promover a integração entre a instituição, a comunidade e os setores produtivos com a finalidade de compreender suas necessidades, estabelecer parcerias com entidades públicas e privadas para a troca de tecnologia, cooperação técnica e a prospecção de outras fontes de financiamento.

Referendando as opiniões apresentadas pelos respondentes, Brandão (2012, p. 9) destaca que

dentre os múltiplos significados da expressão comunicação pública, é possível encontrar um ponto comum de entendimento que é aquele que diz respeito a um processo comunicativo que se instaura entre o Estado, o governo e a sociedade com o objetivo de informar para a construção da cidadania. É com este significado que no Brasil o conceito vem sendo construído, sobretudo por força da área acadêmica que tem direcionado seu pensamento para esta acepção.

No tocante ao Planejamento e Avaliação, destacou-se a necessidade de se criar e/ou revisar os regulamentos e o próprio PI na perspectiva que este se torne mais eficiente e venha refletir a realidade que se apresenta e às necessidades da instituição. Também foi mencionada a necessidade de se desenvolver uma cultura organizacional que estimule os servidores a trabalharem com ênfase no planejamento. Tais aspectos podem ser observados nas falas dos respondentes (R55, R95 e R25).

A falta de normativas que sejam ao mesmo tempo eficientes e eficazes na aplicação do PDI (R55).

Alguns indicadores precisam ser revistos, pois não há clareza do que se pretende alcançar. Há problemas de definição de conceitos e de metas (R95). O PDI deve ser difundido culturalmente entre todos os níveis hierárquicos da Instituição, para que não fique apenas um diálogo estratégico, porém, sem operacionalização (R25). 
Segundo Carvalho (1979, p. 16),

o planejamento é compreendido como um processo lógico que auxilia o comportamento humano racional na consecução de atividades intencionais voltadas para o futuro. Esse comportamento racional, objetivando a ação futura constitui a essência do planejamento.

Sobre missão e PDI, foi destacado o respeito às tradições da Rede Federal, mas de forma imperiosa os respondentes elencaram a necessidade das instituições atentarem para executar sempre o que foi planejado, procurando equilibrar as demandas do ensino com as demandas da área administrativa e de gestão de pessoas, com o objetivo de alinhar as práticas aos valores institucionais. Tais aspectos podem ser observados nas falas dos respondentes (R63 e R85).

PDI é principalmente formulado visando o ensino, pouco temos participação no âmbito administrativo e ainda mais no âmbito de gestão de pessoas (R63). Há um descolamento entre as metas do PDI e as práticas adotadas no instituto (R85).

As respostas dos entrevistados estiveram alinhadas ao apresentado por Kunsch (2005). O autor descreve a missão como a razão de ser de uma organização, expressando seu papel junto à sociedade, por meio da exposição de seus propósitos e realizações bem como os serviços ou produtos que oferece.

\subsubsection{Aspectos pedagógicos e metodológicos}

A Figura 6 apresenta o aglomerado das respostas relacionadas aos aspectos pedagógicos e metodológicos. Dentre as três dimensões identificadas, destacou-se a dimensão "5: Políticas de Pessoal", com 28 opiniões, ou 57\% do total das respostas para este aspecto, seguido da dimensão "2: Políticas para o ensino, pesquisa e extensão", com 15 opiniões, ou $31 \%$ do total das opiniões e a dimensão "7: Infraestrutura física", com 6 opiniões ou 12\% do total das respostas. 
Figura 6 - Percepções dos gestores sobre os aspectos pedagógicos e metodológicos

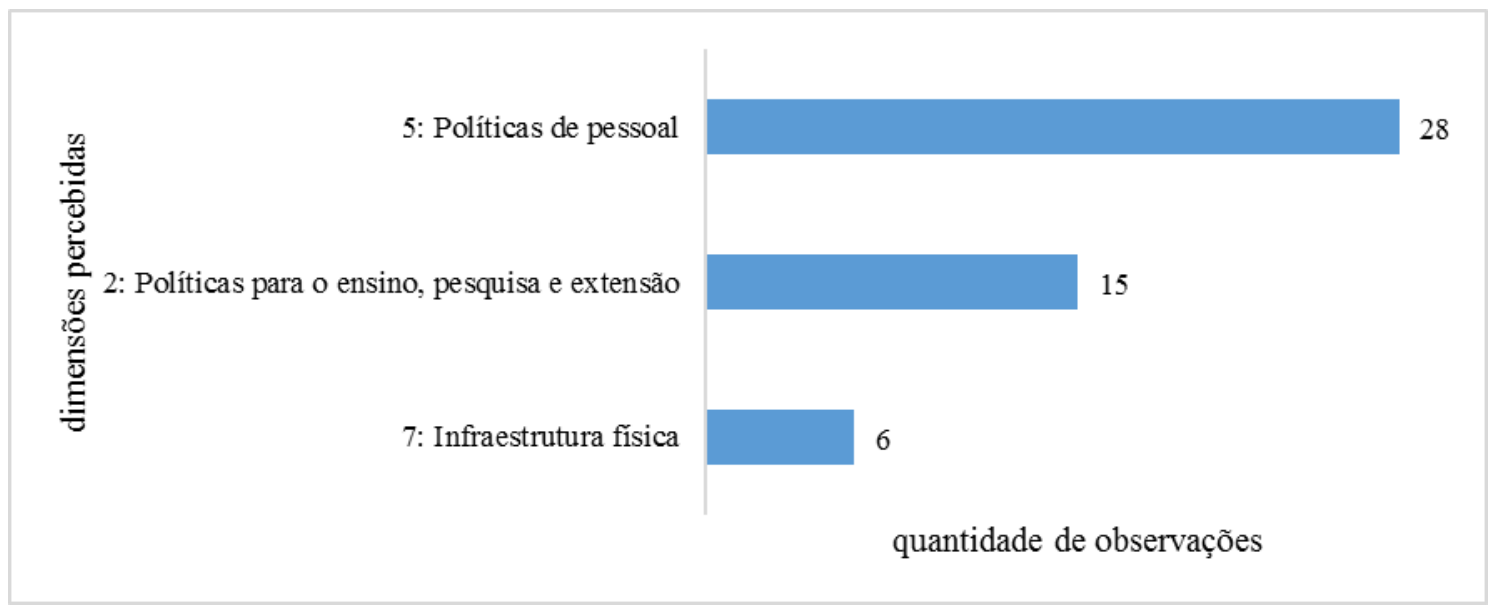

Fonte: Elaborado pelo autor

No que compete à política de pessoal, ficou evidenciado a necessidade da valorização dos profissionais que trabalham nos institutos, para tal foi sugerido o desenvolvimento de uma política permanente de formação continuada dos servidores, com atenção especial para a formação profissional voltada para a atuação no serviço público e em suas áreas específicas. Também foi destacada a necessidade do correto dimensionamento da força de trabalho nas instituições tomando por referencial metodológico a gestão por competência e a gestão do conhecimento. Tais aspectos podem ser observados nas falas dos respondentes (R04, R37 e R84).

Institucionalizar a formação pedagógica docente/técnica para servidores recém-chegados na instituição (R04).

A estrutura organizacional da instituição peca por ser extremamente hierarquizada, por não permitir a gestão por competências (R37).

Se faz necessário a implantação da gestão por competências, como também a gestão do conhecimento no instituto (R84).

Segundo Carvalho (2011, p. 325) apud Oliveira, Machado e John (2016),

a Gestão por competência consiste no que identifica as competências indispensáveis, incluindo conhecimentos e habilidades da eficiência e eficácia profissional, além de apontar as falhas ou deficiências de qualificação para atividades ou serviços especiais.

Para Terra (2005, p. 8), a gestão do conhecimento significa

organizar as principais políticas, processos e ferramentas gerenciais e tecnológicas à luz de uma melhor compreensão dos processos de geração, identificação, validação, disseminação, compartilhamento, proteção e uso dos 
conhecimentos estratégicos para gerar resultados (econômicos) para a empresa e benefícios para os colaboradores internos e externos (stakeholders).

Ainda sobre política de pessoal, foi sugerido a implementação de uma política permanente de formação pedagógica voltada para os profissionais que atuam diretamente nas atividades de ensino. Também foi pontuado a necessidade do desenvolvimento de cursos de formação de servidores para atuação na gestão, estimulando assim a cultura da meritocracia para o provimento dos cargos comissionados.

No tocante às políticas para o ensino, pesquisa e extensão, além das solicitações para o aprimoramento do Projeto Político Institucional (PPI), destacou-se a necessidade da reestruturação dos planos de curso para que estes venham ter em suas grades curriculares mais aulas práticas e que estas possam utilizar métodos de aprendizagem contemporâneos e em conformidade com o estabelecido no PDI. Tais aspectos podem ser observados nas falas dos respondentes (R09, R94 e R83).

Falta conhecimento sobre quais seriam os aspectos pedagógicos que regem uma instituição que não é nem universidade, nem escola técnica, mas tudo ao mesmo tempo (R09).

Os métodos didáticos devem ser aprimorados frente a revolução tecnológica vivida nos tempos atuais. Deve haver uma inserção maior das novas tecnologias, principalmente de comunicação, nas aulas e atividades (R94). A formação do currículo dos cursos, poderia ser discutido com as entidades que atuam na área, para que não seja somente algo acadêmico, mas de acordo com a realidade da própria comunidade (R83).

Ainda sobre estas políticas, em especial, voltadas ao eixo da pesquisa, foi pontuado a necessidade de se estabelecer uma política institucional voltada para a promoção da inovação tecnológica que contemple a propriedade intelectual, o reconhecimento de patentes e os processos de transferência de tecnologia.

De acordo com Guimarães (2008, p. 7), em sua fundamentação:

o PPI deve expressar uma visão de mundo contemporâneo e do papel da educação superior em face da nova conjuntura globalizada e tecnológica, ao mesmo tempo em que deve explicitar, de modo abrangente, o papel da IES e sua contribuição social nos âmbitos local, regional e nacional, por meio do ensino, da pesquisa e da extensão como componentes essenciais à formação crítica do cidadão e do futuro profissional, na busca da articulação entre o real e o desejável. 
Sobre infraestrutura física, foi evidenciado que, de forma geral, os Institutos Federais, dispõem de uma infraestrutura precária, obsoleta ou inadequada, prejudicando a formação do estudante e, por consequência, sua empregabilidade. Também foi pontuada a necessidade de construção nos campi de um espaço para promoção de atividades culturais como também para viabilizar a integração entre a instituição e a comunidade.

Sobre este aspecto, Vargas (2015, p. 9) esclarece que

o processo de expansão apresenta problemas de ordem estrutural, pois a rapidez na construção de escolas não é acompanhada por uma infraestrutura adequada à melhor formação profissional desses estudantes, em função da ausência de laboratórios equipados, bibliotecas e da quantidade necessária de docentes e técnicos administrativos.

\subsubsection{Aspectos sociais e culturais}

A Figura 7 apresenta o agrupamento das respostas relacionadas aos aspectos sociais e culturais. Dentre as duas dimensões identificadas, destacou-se a dimensão “3: Responsabilidade Social”, com 36 opiniões, ou $82 \%$ do total para este aspecto, seguido da dimensão "9: Política de Atendimento aos Discentes", com 8 opiniões, ou $18 \%$ do total das respostas para este aspecto.

Figura 7 - Percepções dos gestores sobre os aspectos sociais e culturais

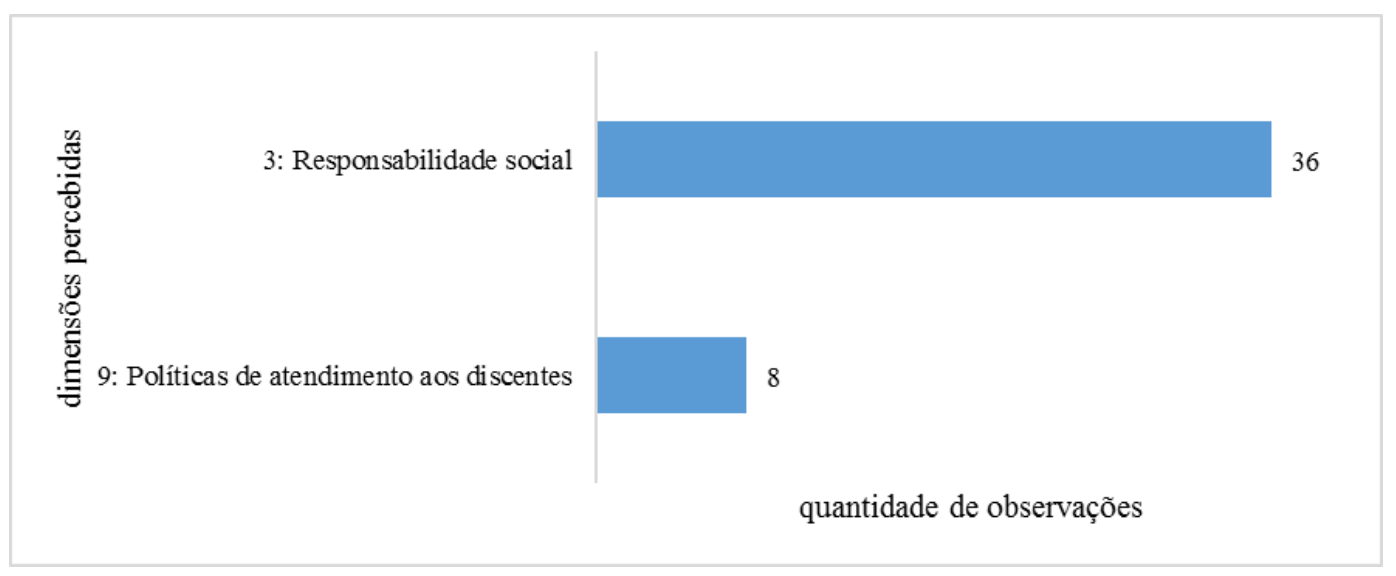

Fonte: Elaborado pelo autor

No tocante à responsabilidade social, os respondentes evidenciaram a necessidade do desenvolvimento de ações institucionais que tratem da diversidade, contemplando o 
fortalecimento da cultura regional, a promoção de ações que atentem para a igualdade de gênero, que versem sobre questões étnico-raciais, que contemplem sexualidade e orientação sexual, que discutam a diversidade religiosa e que tratem da diversidade na instituição em toda sua amplitude. Tais aspectos podem ser observados das falas dos respondentes (R91, R62 e R64).

A heterogeneidade dos alunos e a falta de capacidade de trabalhar com os que tem dificuldade e estão a muito tempo fora da escola é um gargalo, e o Instituto ainda não conseguiu se adequar com essa realidade (R91).

A diversidade e a inclusão são elementos presentes no PDI por voluntarismo e não estão institucionalizados (R62).

Não há no PDI menção sobre questões de credo, de gênero, de sexualidade e de etnia (R64).

Ainda sobre responsabilidade social, também foi destacada a necessidade das instituições desenvolverem ações que combatam a desigualdade social e promovam a igualdade social.

De acordo com Almeida (2008, p. 5),

o termo diversidade, tal qual tem sido amplamente difundido no campo das políticas governamentais, tem relação com as teorias contemporâneas do multiculturalismo e refere-se não só a questões raciais e étnicas, mas também a uma série de outros campos da vida social; fala-se, desta maneira, em diversidade sexual, religiosa, cultural etc.

Sobre políticas de atendimento aos discentes, ficou evidenciado a necessidade de institucionalizar políticas de combate à evasão escolar na perspectiva da promoção da permanência e do êxito do estudante. Também foi pontuado a necessidade de se estabelecer parcerias com os setores produtivos na perspectiva de garantir a inserção do estudante no mundo do trabalho. Tais aspectos podem ser observados nas falas dos respondentes (R62 e R91).

Não há uma política institucional de inclusão e combate à evasão com vistas ao êxito acadêmico (R62).

Neste aspecto falta um grande passo, precisamos de mais parcerias, de mais participação de todos no processo, de forma o promover a inclusão dos alunos no mercado de trabalho (R91). 
Para Queiroz (2010), evasão escolar é o abandono da escola antes da conclusão de uma série ou de um determinado nível. Consiste no ato ou processo de evadir, de fugir, de escapar ou esquivar-se dos compromissos assumidos ou por fim a assumir.

\subsubsection{Aspectos legais e administrativos}

A Figura 8 apresenta o conjunto das respostas relacionadas aos aspectos legais e administrativos. Dentre as duas dimensões identificadas, destacou-se a "6: Organização e Gestão da Instituição", com 37 opiniões, ou 82\% do total das opiniões para este aspecto, seguida da dimensão "10: Sustentabilidade financeira", com 8 opiniões, o que corresponde a $18 \%$ do total das respostas para este aspecto.

Figura 8 - Percepções dos gestores sobre os aspectos legais e administrativos

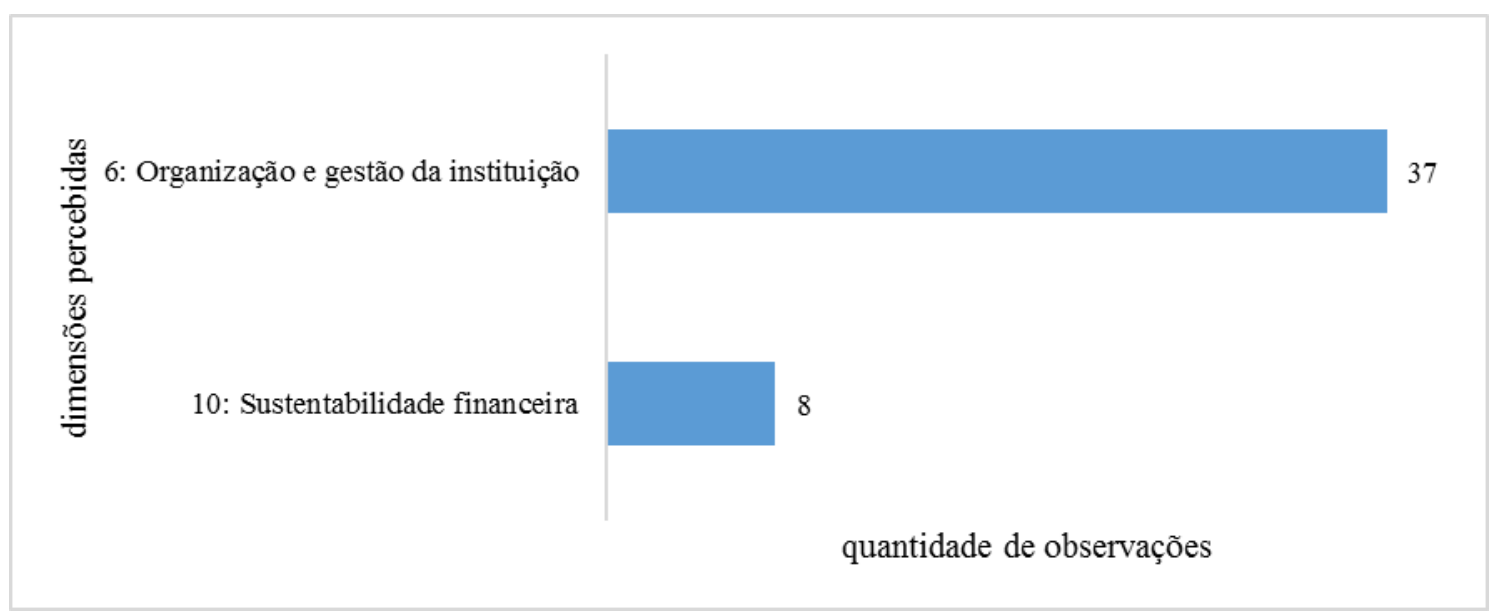

Fonte: Elaborado pelo autor

No que se refere à organização e gestão da instituição, foi destacado que o imediatismo, reativismo e as atitudes discricionárias atrapalham o planejamento. Em contrapartida, também foi evidenciado a necessidade de estimular ações que fortaleçam a gestão democrática e participativa com o fortalecimento das comissões como a Comissão Própria de Avaliação (CPA), Comissão Interna de Supervisão (CIS) do Plano de Carreira dos Cargos Técnicoadministrativos em Educação (PCCTAE), Comissão Própria de Pessoal Docente (CPPD) e a Comissão de Ética (COET) inclusive para atuação de forma consultiva para o tratamento de questões financeiras e de dimensionamento de pessoal. 
Ainda nesta dimensão, também foi pontuado que a burocracia e a centralização de poder, de processos e de orçamento dificultam a contratação de bens e serviços e atrasam as atividades da instituição. Tais aspectos podem ser observados nas falas dos respondentes (R62 e R66).

Não há desenho de processos o que abre espaço para opiniões e interferência da vontade dos gestores exacerbando seu poder discricionário (R62).

Existe uma dificuldade na operacionalização de muitas ações, frente as inúmeras legislações e impedimentos administrativos para a rápida resposta às demandas da sociedade (R66).

Neste aspecto Schuch (2007, p. 56), esclarece que

a gestão democrática é um processo em constante construção, que tem na sala de aula seu embrião, oportunidade primeira de vivência democrática do aluno, professor, dos pais, da direção e dos funcionários. Trata-se de um processo que se faz no dia-a-dia da escola. Por mais que esteja posta na Lei, se não houver pessoas preparadas para o seu exercício, ela não acontecerá na prática.

No tocante à sustentabilidade financeira, foi avaliado pelos respondentes que o planejamento orçamentário nas instituições é ineficiente, também foi evidenciado que as limitações e cortes orçamentários atrapalham a execução do que foi planejado. Todavia, para contrapor as limitações orçamentárias, foi sugerido que os Institutos Federais buscassem fontes externas de financiamento para auxiliar na execução do que foi planejado. Tais aspectos podem ser observados nas falas dos respondentes (R83 e R41).

O planejamento do orçamento e as finanças, necessitam de uma maior clareza, de forma que as pessoas compreendam os gráficos e planilhas que são apresentados (R83).

A escassez de recursos inviabiliza a realização de muitas ações planejadas, atenta-se para a necessidade da gestão otimizar e propiciar elementos que busquem alimentar o fundo orçamentário com ações de cooperação técnica e parcerias institucionais. (R41).

No tocante a prospecção de fontes externas de financiamento, Corbucci (2004, p. 30)

esclarece que

a busca de fontes alternativas de recursos pode ser vista como iniciativa de sobrevivência institucional que permitiu às IFES com mais larga tradição na produção de conhecimento as segurar, em diferentes níveis e graus, a manutenção de seus quadros técnicos, o cumprimento de suas funções essenciais e a reposição e/ou aquisição de equipamentos. 


\subsubsection{Análise do perfil dos respondentes}

A Figura 9 apresentou o resultado agregado em percentual do questionamento "com que frequência você faz uso do PDI? ". Como possibilidades de respostas haviam opções de multipla escolha com a intenção de identificar qual a periodicidade do uso do PDI por parte do respondente.

Figura 9 - Respostas à pergunta: com que frequência você faz uso do PDI?

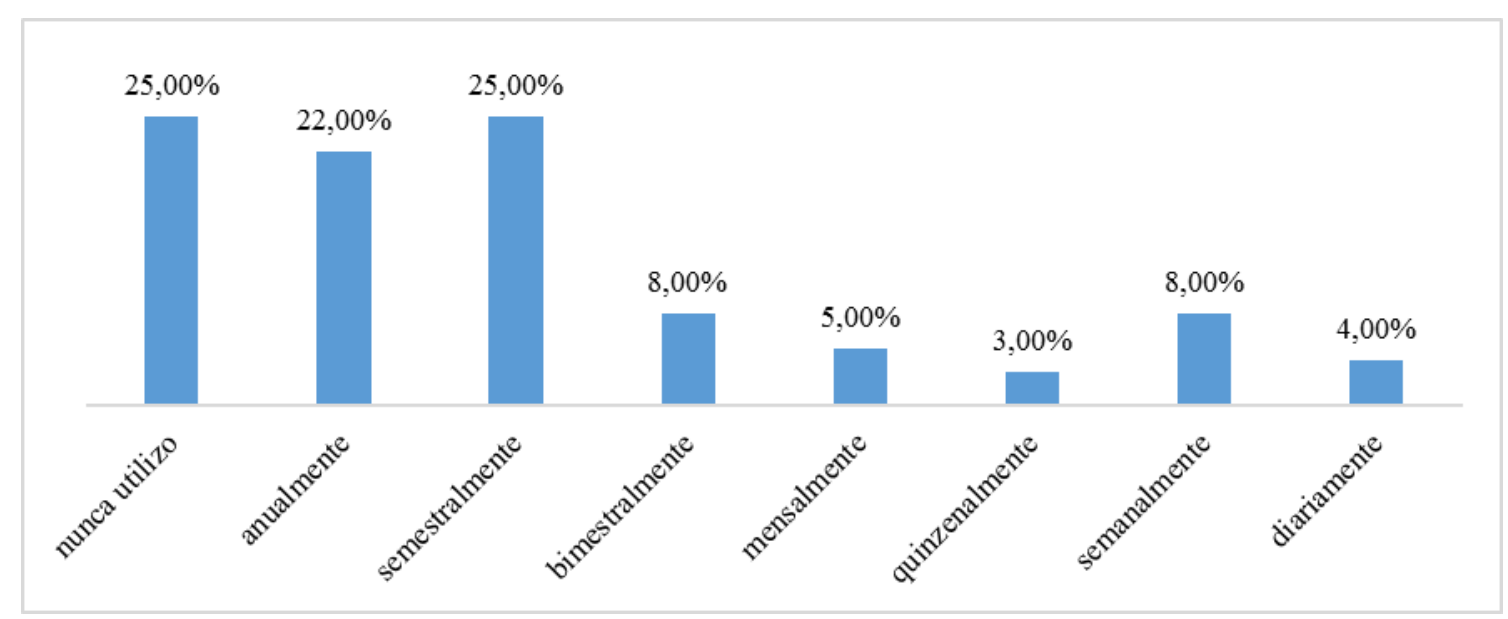

Fonte: Elaborado pelo autor

Chama-se a atenção para a constatação de que $25 \%$ dos respondentes informaram que nunca utilizam o PDI em suas atividades. Outros $23 \%$ informaram que utilizam o PDI anualmente e outra expressiva parcela, $25 \%$ dos respondentes asseguraram que utilizam o PDI semestralmente. Desta forma, podemos inferir que $72 \%$ dos respondentes ou não acompanham o PI por meio do PDI, ou se acompanham, o fazem de forma muito esporádica. Tal aspecto pode ser observado nas falas dos respondentes (R25).

O PDI, por ser uma ferramenta nova de gestão, sofre com a dificuldade de operacionalização, uma vez que, as pessoas não possuem o hábito de utilizar de manuais para cumprir com o planejamento, objetivos e metas estabelecidas. (R25)

No tocante ao monitoramento das atividades, Robbins (1978, p. 449), apud Kich e Pereira (2011), esclarece que

[...] o processo de monitoramento de atividades para determinar se as unidades individuais e a própria organização estão obtendo e utilizando seus recursos 
eficaz e eficientemente, de modo a atingir seus objetivos, e, quando isto não está sendo conseguido, implementação da ação corretiva.

No que se refere à qualificação profissional, a Figura 10, apresenta a distribuição percentual sobre o questionamento “qual o seu nível de escolaridade atual?”, como resultado, $40 \%$ dos respondentes informaram que são especialistas, 35\% alcançaram o grau de mestres e $15 \%$ são doutores.

Se consideramos que um dos principais requisitos para ocupação de cargos de gestão é ter qualificação para tal investidura, se unidas a população de especialistas, mestres, doutores e pós-doutores, temos um total de 95\% com qualificação acima do requisito necessário para investidura no cargo, o que demonstra um excepcional nível de qualificação dos respondentes.

Figura 10 - Respostas à pergunta: qual o seu nível de escolaridade atual?

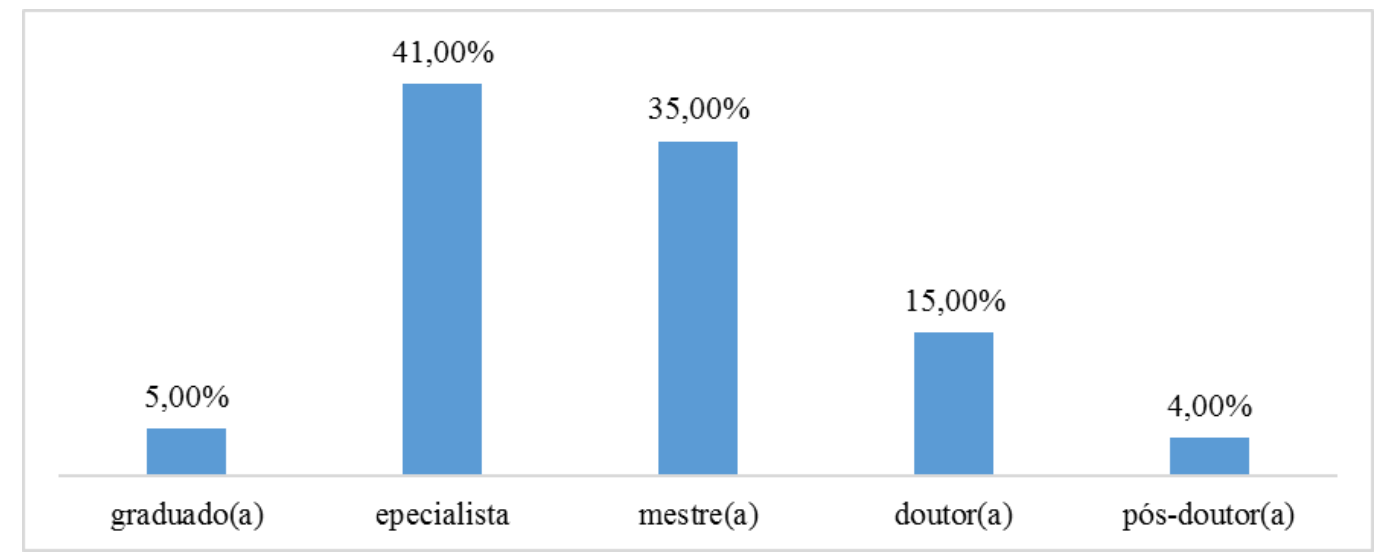

Fonte: Elaborado pelo autor

Como questão complementar, arguimos os gestores se "nas suas atividades no Instituto, você atua na sua área de formação?”. A Figura 11 ilustra estas respostas, e constata de forma expressiva, que $73 \%$ dos respondentes informaram que atuam nos Institutos Federais exercendo atividades na mesma área de formação.

Tal constatação denota o interesse vocacional do entrevistado com o desenvolvimento de suas atividades. Sobre esta questão Bilhim (2001) salienta que o domínio das competências, profissionais e emocionais, para o bom desempenho do posto de trabalho, é um requisito indispensável para que a organização forneça uma boa qualidade de serviço. 
Figura 11 - Respostas à pergunta: nas suas atividades, você atua na sua área de formação?

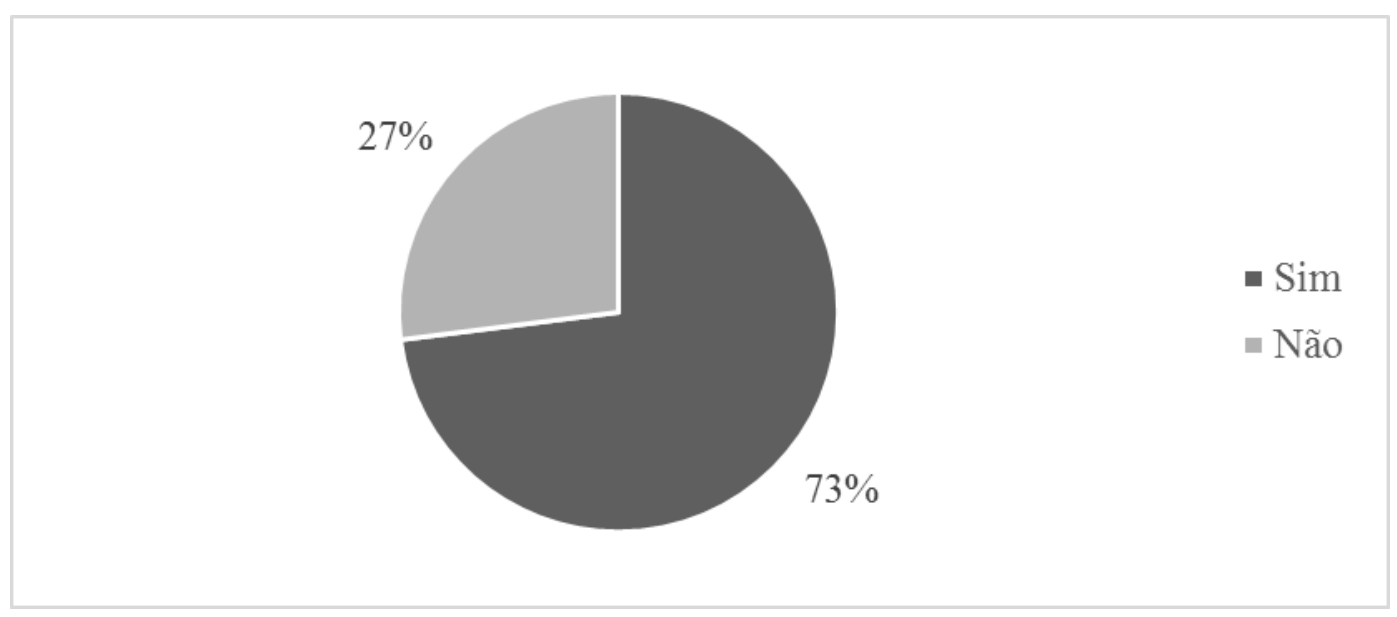

Fonte: Elaborado pelo autor

\section{CONSIDERAÇÕES FINAIS}

Como visto, mesmo sendo uma determinação legal relativamente recente, o PDI, originalmente elaborado para atender às necessidades de planejamento, acompanhamento e avaliação das IES, se adequou às necessidades dos Institutos Federais e, mesmo não contemplando todas as suas especificidades, desde a sua primeira edição, foi de fundamental importância para nortear suas ações, pois como instituições recentes, careciam de um instrumento para orientar o seu planejamento.

Os Institutos Federais além de ofertarem ensino superior, pós-graduação, e contemplarem a pesquisa e a extensão, tem como sua principal característica a oferta de cursos regulares de formação profissional e tecnológica. Diante desta singularidade, por melhor se enquadrar na gestão democrática e participativa, estabelecidas como forma de gestão para estas autarquias federais, o planejamento estratégico foi a metodologia de trabalho adotada para as instituições participantes da Rede Federal.

De forma geral, a execução do PDI em questão foi considerada satisfatória, com o atendimento de $72 \%$, do total das metas estabelecidas para o período analisado. Por intermédio dos relatórios de gestão, foi possível constatar o cumprimento dos objetivos gerais para as áreas de ensino e gestão, com destaque para as metas relacionadas à oferta de cursos técnicos, 
superiores e especializações, bem como a ampliação da infraestrutura física, a melhoria da gestão pedagógica e a articulação entre ensino, pesquisa e extensão.

Contudo, objetivos importantes relacionados a Educação a Distância (EAD), a oferta de cursos de pós-graduação strictu sensu e a implementação do programa de qualidade de vida ficaram prejudicados em parte, pela falta de orçamento e também pela carência de pessoal com qualificação específica para o andamento destas demandas.

$\mathrm{Na}$ análise documental, os Relatórios de Gestão também evidenciaram que o quantitativo das metas executadas foi consideravelmente superior ao inicialmente previsto, chegando a ser quatro vezes superior às metas previstas no PDI 2009/2013 do IFB. De acordo com os relatórios, tal ajuste se fez necessário em decorrência da implantação de programas federais voltados para a educação profissional como o PRONATEC e à terceira fase de expansão da Rede Federal.

Desta forma, por mais que a maioria das metas planejadas e alcançadas no período de vigência do PDI 2009/2013 do IFB não constassem no planejamento original, pôde-se constatar que elas foram de suma importância para que a instituição pudesse se ajustar às novas realidades que se apresentaram no decorrer do quinquênio e, por consequência, obtivesse sucesso na realização de seus objetivos.

Atendendo ao segundo objetivo desta pesquisa, para melhor compreender as especificidades do planejamento institucional dos Institutos Federais, com base na análise de conteúdo aplicada nas respostas do questionário eletrônico semiestruturado, pôde-se identificar os gargalos por eles elencados na utilização do PDI como ferramenta de planejamento em suas instituições.

Dentre os gargalos identificados pelos gestores, no que se refere aos aspectos políticos e institucionais, podemos destacar a necessidade de aprimorar o processo de comunicação da 
instituição com a sociedade, uma vez que foi percebida a preocupação dos gestores com o desconhecimento da comunidade do que venha a ser a própria instituição.

Outro gargalo evidenciado pelos gestores está relacionado aos aspectos sociais e culturais, uma vez que eles identificaram a necessidade dos Institutos Federais desenvolverem políticas permanentes que contemplem a diversidade em toda sua amplitude, inclusive com ações que identifiquem e fortaleçam a diversidade e heterogeneidade da própria instituição.

Ainda sobre a percepção dos gestores no que se refere ao PDI, nos aspectos legais e administrativos ficou evidenciado que os Institutos Federais precisam ainda aprimorar sua organização e gestão, como sugestão foi colocado o fortalecimento da gestão democrática e participativa e busca de fontes externas de financiamento para superar os contingenciamentos orçamentários.

No que se refere às contribuições relacionadas aos aspectos pedagógico e metodológicos, a opinião mais recorrente foi a necessidade dos Institutos Federais estabelecerem uma política permanente de formação continuada dos servidores com atenção especial para a atuação no serviço público e em suas áreas específicas.

Ao analisar a execução do PDI 2009/2013 do IFB e os gargalos percebidos pelos gestores da Rede Federal, pôde-se constatar que parte das ações não planejadas e dos gargalos identificados ocorrem pelas especificidades dos Institutos Federais, uma vez que tanto seu público quanto sua finalidade se diferenciam das demais IES no Brasil. Diferenças estas que, por falta de referencial para a elaboração do planejamento que reflita a realidade dos Institutos Federais nem sempre conseguem ser percebidas pelo planejamento institucional.

Desta forma, a avaliação da Execução do Planejamento do IFB, bem como a apresentação dos gargalos identificados pelos gestores, servirá de instrumento para a formulação de planejamentos estratégicos mais realísticos e conscientes, centrados nas possibilidades e respeitando as peculiaridades existentes nos Institutos Federais. 


\section{REFERÊNCIAS BIBLIOGRÁFICAS}

ALMEIDA, Nina Paiva. Diversidade na universidade: O BID e as políticas educacionais de inclusão étnico-racial no Brasil. Rio de Janeiro, UFRJ/MN/PPGAS 2008.

ALMEIDA, M. I. R. Manual de planejamento estratégico: desenvolvimento de um plano estratégico com a utilização de planilhas de excel. 2.ed. São Paulo: Atlas, 2009.

ARGUIN, G.O. O Planejamento Estratégico no Meio Universitário. Brasília, 1988.

ATHANÁZIO, M. M. Processo de planejamento estratégico em universidade pública: o caso da Universidade Federal do Pará (UFPA). Dissertação de Mestrado. UFRN, 2010.

BARDIN, Laurence. Analise de conteúdo. São Paulo: Edições 70, 2011.

BATEMAN, T. S. Administração: novo cenário competitivo. 2. ed. São Paulo: Atlas, 2006.

BERTERO, C. O. Rumos da Estratégia Empresarial. RAE-Revista de Administração de Empresas, v. 35, n. 2, mar-abr, 1995.

BILHIM, João de Abreu de Faria. Questões atuais de gestão de recursos humanos. Lisboa: Editora do Instituto Superior de Ciências Sociais e Políticas, 2001.

BRANDÃO, Elizabeth Pazito. Conceito de comunicação pública. In: DUARTE, Jorge (Org.). Comunicação Pública: Estado, Mercado, Sociedade e Interesse Público. 3. ed. São Paulo: Atlas, 2012.

BRASIL. Constituição (1988). Constituição da República Federativa do Brasil. Brasília: Senado Federal, 1988.

Decreto $\mathrm{N}^{\mathrm{0}} 7.566$, de 23 de setembro de 1909. Cria nas Capitais dos Estados da República Escolas de Aprendizes Artífices para o ensino profissional primário e gratuito. Coleções de Leis do Brasil. Imprensa Nacional: Rio de Janeiro, 26 set. 1909. Disponível em: <http://www.senado.gov.br>. Acesso em: 30 mai. 2015.

Decreto $\mathrm{N}^{\circ}$ 19.444, de $1^{\circ}$ de dezembro de 1930. Dispõe sobre os serviços que ficam e cargo do Ministério da Educação e Saúde Pública, e dá outras providências. Coleções de Leis do Brasil. Imprensa Nacional: Rio de Janeiro, 25 dez. 1930. Disponível em: <http://www.senado.gov.br>. Acesso em: 30 mai. 2015.

Decreto $\mathrm{N}^{\mathrm{o}} 2.208$, de 17 de abril de 1997 . Dispõe sobre a regulamentação do $\S 2^{\circ}$ do art. 36 e os Arts. 39 a 42 da Lei No 9.394, de 20 de dezembro de 1996, que estabelece as diretrizes e bases da educação nacional. Diário Oficial da União, Brasília, DF, 18 abr. 1997. 
Decreto $\mathrm{N}^{\circ}$ 5.773, de 09 de maio de 2006. Dispõe sobre o exercício das funções de regulação, supervisão e avaliação de instituições de educação superior e cursos superiores de graduação e sequenciais no sistema federal de ensino. Diário Oficial da União, Brasília, DF, 10 mai. 2006c.

Decreto-lei $N^{\circ}$ 4.073, de 30 de janeiro de 1942. Lei orgânica do ensino industrial, que estabelece as bases de organização e de regime do ensino industrial que é o ramo de ensino, de grau secundário, destinado à preparação profissional dos trabalhadores da indústria e das atividades artesanais e, ainda, dos trabalhadores dos transportes, das comunicações e da pesca. Coleção das Leis do Brasil, Rio de Janeiro, DF, 31 dez. 1942a.. Disponível em: <http://www3.dataprev.gov.br/SISLEX/paginas/24/1942/4073.htm>. Acesso em: 30 mai. 2015.

Decreto-lei $\mathrm{N}^{\circ} 4.127$, de 25 de fevereiro de 1942. Estabelece as bases de organização da rede federal de estabelecimentos de ensino industrial. Coleção das Leis do Brasil, Rio de Janeiro, DF, 31 dez. 1942b. Disponível em: < http://www2.camara.leg.br/legin/fed/declei/1940-1949/decreto-lei-4127-25-fevereiro-1942414123-publicacaooriginal-1-pe.html>. Acesso em: 30 mai. 2015.

Lei $N^{o}$ 378, de 13 de janeiro de 1937. Dá nova, organização ao Ministério da Educação e Saúde Pública. Coleções de Leis do Brasil. Imprensa Nacional: Rio de Janeiro, 13 jan. 1937. Disponível em: 〈http://www.senado.gov.br〉. Acesso em: 30 mai. 2015.

Lei $\mathrm{N}^{\circ} 3.552$, de 16 de fevereiro de 1959. Dispõe sobre nova organização escolar e administrativa dos estabelecimentos de ensino industrial do Ministério da Educação e Cultura, e dá outras providências. Diário Oficial \{da\} República Federativa do Brasil, Rio de Janeiro, DF, 17 fev. $1959 . \quad$ Disponível em: <http://www3.dataprev.gov.br/SISLEX/paginas/42/1959/3552.htm>. Acesso em: 30 mai. 2015.

Lei $N^{\circ}$ 6.545, de 30 de junho de 1978. Dispõe sobre a transformação das Escolas Técnicas Federais de Minas Gerais, do Paraná e Celso Suckow da Fonseca em Centros Federais de Educação Tecnológica, e dá outras providências. Diário Oficial da União, Brasília, 1978.

Lei No 8.948 de 08 de dezembro de 1994. Dispõe sobre a instituição do Sistema Nacional de Educação Tecnológica e dá outras providências. Diário Oficial da União. Poder Executivo, Brasília, DF, 9 dez. 1994a. Seção I.

Lei $\mathrm{N}^{\circ}$ 8.958, de 20 de dezembro de 1994. Dispõe sobre as relações entre as instituições federais de ensino superior e de pesquisa científica e tecnológica e as fundações de apoio e dá outras providências. Diário Oficial da União, Poder Executivo, Brasília, DF, 21 dez. 1994b. Seção I.

Lei $\mathrm{N}^{\circ}$ 9.394, de 20 de dezembro de 1996. Estabelece as diretrizes e bases da educação nacional. Diário Oficial da União, Poder Executivo, Brasília, DF, 23 dez. 1996. 
Lei No 9.649 de 27 de maio de 1998. Dispõe sobre a organização da Presidência da República e dos Ministérios e dá outras providências. Diário Oficial da União, Poder Executivo, Brasília, DF, 27 mai. 1998.

Lei $N^{\circ} 10.861$, de 14 de abril de 2004. Institui o Sistema Nacional de Avaliação da Educação Superior - SINAES e dá outras providências. Diário Oficial da União. Brasília, DF, 15 abr. 2004. Seção 1, p. 3-4.

Lei $\mathrm{N}^{\circ} 11.195$, de 18 de novembro de 2005 . Dá nova redação ao $\S 5^{\circ}$ do art. $3^{\circ}$ da Lei no 8.948, de 8 de dezembro de 1994. Diário Oficial da União, Poder Executivo, Brasília, DF, 18 nov. 2005.

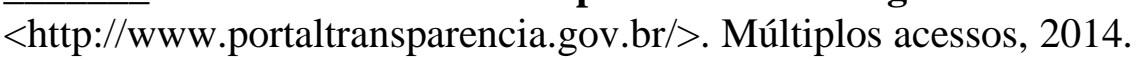

MEC. Ministério da Educação. Institutos Federais lei 11.892, de 29/11/2008: comentários e reflexões. Organizado por Caetana Juracy Resende Silva. Natal: IFRN, 2009. $70 \mathrm{p}$.

Portaria $\mathbf{N}^{\circ}$ 300, de 30 de janeiro de 2006. Aprova, em extrato, o Instrumento de Avaliação Externa de Instituições de Educação Superior do Sistema Nacional de Avaliação da Educação Superior - SINAES. [2006a]. Disponível em: < http://download.inep.gov.br/download/superior/2006/avaliacao_institicional/Portaria_n300_3 0_01_06.pdf >. Acesso em: 30 mai. 2015.

Portaria $\mathbf{N}^{\circ}$ 563, de 21 de fevereiro de 2006. Aprova, em extrato, o Instrumento de Avaliação de Cursos de Graduação do Sistema Nacional de Avaliação da Educação Superior - SINAES. Brasília, DF: Gabinete do Ministro, [2006b]. Disponível em: <http://www.cmconsultoria.com.br/legislacao/portarias/2006/por_2006_563_MEC.pdf>. Acesso em: 30 mai. 2015.

Portaria $\mathrm{N}^{\circ}$ 92, de 31 de janeiro de 2014. Aprova, em extrato, os indicadores do Instrumento de Avaliação Institucional Externa para os atos de credenciamento, recredenciamento e transformação de organização acadêmica, modalidade presencial, do Sistema Nacional de Avaliação da Educação Superior - SINAES. Diário Oficial da União. Brasília, ano n. 151, Seção 1, p-5, 04 fev. 2014.

Sistema de Acompanhamento de Processos das Instituições de Ensino Superior (SAPIEnS): Instruções para elaboração de plano de desenvolvimento institucional. Atualizado em 05/06/2007. Disponível em: <www4.mec.gov.br/sapiens/pdi.html>. Acesso em: 30 mai. 2015.

- IFB. Instituto Federal de Brasília. Plano de Desenvolvimento

Institucional: PDI 2009/2013. Brasília: IFB, 2009. Aprovado ad referendum pelo reitor substituto no dia $11 \mathrm{fev} .2011$. 
INEP. Portaria $\mathrm{n}^{\circ} .4$, de 13 de janeiro de 2005. Implanta o Instrumento de Avaliação Institucional Externa para fins de credenciamento e recredenciamento de universidades. Diário Oficial da União, Brasília, DF, n. 10, 14 jan. 2005. Seção 1, p. 24. Disponível em: <http://pesquisa.in.gov.br/imprensa/jsp/visualiza/index.jsp?jornal=1\&pagina $=24 \&$ data $=14 / 01 / 2005>$. Acesso em: 30 mai. 2016 .

- Secretaria de Educação Profissional e Tecnológica. Institutos Federais de Ciência, Educação e Tecnologia: concepção e diretrizes. Brasília: MEC: SETEC, 2008. Disponível em: <http://portal.mec.gov.br/setec/arquivos/pdf3/ifets_livreto.pdf>. Acesso em: 07 abr. 2016.

BRESSER PEREIRA, L. C. Da administração burocrática à gerencial. Revista do Serviço Público. Ano 47, vol.120, n.1, jan./abr. 1996.

CAMPOS, V. F. Gerenciamento da rotina do trabalho do dia-a-dia. Belo Horizonte: Editora de Desenvolvimento Gerencial, 2001.

CARVALHO, Horácio Martins de. Introdução à teoria do planejamento. São Paulo: Brasiliense, 1979.

CARVALHO, João Gilberto. Programa Mulheres Mil em Arraial do Cabo: extensão e inclusão com base na sustentabilidade. Extramuros, Petrolina-PE, v. 1, n. 2, p. 92-99, ago./dez. 2013. Disponível em: <http://periodicos.univasf.edu.br/index.php/extramuros/article /viewFile/278/123>. Acesso em: 02 mai. 2016.

CELESTINO, M. S.; SILVA, J. D. G.; AÑES, M. E. M. O balanced scorecard comoframework para a ação estratégica na indústria petrolífera brasileira. In: José Dionísio Gomes da Silva; Otacílio dos Santos Silveira Neto. (Org.). Reflexões sobre os aspectos financeiros, societários e tributários do setor de petróleo, gás e biocombustíveis. 1ed. Natal - RN: Polyprint, 2012, v. 1, p. 283-310.

COLOMBO, S. S. Gestão Educacional: uma nova visão. São Paulo: Artmed, 2004.

CORBUCCI, P. R. Financiamento e democratização do acesso à educação superior no Brasil: da deserção do estado ao projeto de reforma. Educ. Soc., 69 Campinas, v. 25, n. 88, p. 677 - 701, out. 2004. Disponível em: <www.scielo.br/pdf/es/v25n88/a03v2588.pdf>. Acesso em: 02 mai. 2016.

COSTÁBILE, L. T., Desenvolvimento de um plano estratégico em uma instituição de ensino superior. Dissertação de Mestrado. Faculdade de Engenharia Mecânica, Universidade Estadual de Campinas, 2007.

CUNHA, Cristiano J. C. A. Planejamento Estratégico em Universidades. Florianópolis: Publicação do NEST- Núcleo de Estudos - Departamento de Engenharia de Produção e Sistemas, Universidade Federal de Santa Catarina, 1995. 
FISCHMANN, A.; ALMEIDA, M. I. Planejamento estratégico na prática. Segunda Ed. São Paulo: Editora Atlas, 2009.

GELBCKE, F.; MATOS, E.; SCHMIDT, I. S.; MESQUITA, M. P. L. de; PADILHA, M. F. C. Planejamento estratégico participativo: um espaço para a conquista da cidadania profissional. Texto e Contexto Enfermagem, Florianópolis, v. 15, n. 3, p. 515-520, 2006.

GIL, Antonio Carlos. Como elaborar projetos de pesquisa. 5. ed. São Paulo: Atlas, 2008.

Guimarães, A. M. P. Canais de Atendimento ao aluno em Instituições de Ensino particulares na cidade de São Paulo: um estudo exploratório. São Paulo: UAM, 2008. 128 f. Dissertação (Mestrado em hospitalidade), Faculdade Anhembi Morumbi, São Paulo, 2008.

KAUFMAN, Roger. Strategic planning plus: an organizational guide. Flenview: Scott Foresman, 1991.

KICH, Juliane Inês Di Francesco; PEREIRA, Maurício Fernandes. Planejamento estratégico: os pressupostos básicos para uma implantação eficaz. São Paulo: Atlas, 2011.

KUNSCH, Margarida Maria Krohling. Planejamento de Relações Públicas na Comunicação Integrada. São Paulo: Summus, 2003.

KWASNICKA, E. L. Introdução a Administração. 6. ed. 4 reimpr. São Paulo: Atlas, 2007.

MEYER Jr., V. Considerações sobre o planejamento estratégico na universidade. In: FINGER, Almeri Paulo. Universidade: organização, planejamento, gestão. Florianópolis, UFSC/ CPGA/NUPEAU. 1988. p.53-69.

MEYER Jr., V. Planejamento Estratégico: Uma renovação na gestão das instituições universitárias. Brasília: Seminário - A administração universitária rumo ao ano 2.000, 20 p., 1991.

NUNES, R. C. P. O desenvolvimento colaborativo de projetos de engenharia e arquitetura apoiado por um gerenciador de documentos. 2004. 155 f. Tese (Doutorado em Engenharia) - Programa de Pós-graduação em Engenharia. Universidade Federal do Rio de Janeiro, Rio de Janeiro, 2004.

OLIVEIRA, Djalma de Pinho Rebouças de. Planejamento estratégico: conceitos, metodologia e prática. 25. ed. São Paulo: Atlas, 2008.

OLIVEIRA, V. S. O.; MACHADO, M. C. R.; JOHN, E. Sistema de gestão por competência em pequena empresa: um estudo de caso na empresa Alfa Ltda. In: ENCONTRO DE ESTUDOS EM EMPREENDEDORISMO E GESTÃO DE PEQUENAS EMPRESAS (EGEPE), 9., 2016, Passo Fundo. Anais do IX Encontro de Estudos sobre Empreendedorismo e Gestão de Pequenas Empresas. Passo Fundo: EGEPE, 2016. 
PALUDO, A. V. Administração Pública: teorias e questões. Rio de Janeiro: Elsevier, 2012.

PIOVESAN, A.; TEMPORINI, E. R. Pesquisa exploratória: procedimento metodológico para o estudo de fatores humanos no campo da saúde pública. Rev. Saúde Pública. 1995; 29(4):31825 .

QUEIROZ, Lucineide Domingos. Um estudo sobre a evasão escolar: para se pensar na inclusão escolar. 2010. Disponível em: <http://www.amped.org.br/>. Acesso em: 02 fev. 2016.

REZENDE, D. A. Planejamento estratégico para organizações privadas e públicas: guia prático para elaboração de projeto e plano de negócios. Rio de Janeiro: Brasport, 2008.

SCHUCH, Cleusa Conceição Terres. Implementação da política da autonomia financeira em duas escolas públicas estaduais do Rio Grande do Sul: um estudo de caso, Dissertação de Mestrado do Programa de Pós-graduação em Educação da Universidade Federal do Rio Grande do Sul/UFRGS, 2007, Porto Alegre/RS.

SILVA, Renato. Balanced Scorecard - BSC: gestão de ensino superior, gestão profissionalizada e qualidade de ensino para instituições de ensino superior privado. Curitiba: Juruá, 2008.

TERRA, J. C. C. Gestão do Conhecimento: o grande desafio empresarial. Rio de Janeiro: Campus, 2005.

THIOLLENT, Michel. Metodologia da pesquisa-ação. São Paulo: Cortez, 1985.

TRIVIÑOS, Augusto N. S. Introdução à pesquisa em ciências sociais: a pesquisa qualitativa em educação. São Paulo: Atlas, 1987.

VARGAS, A. C. L. A Política de Educação Profissional e Tecnológica nos anos 2000: novos marcos para a formação da classe trabalhadora. In: Colóquio Nacional: A produção do conhecimento em Educação Profissional, 3., 2015, Natal. Anais eletrônicos... Natal: IFRN, 2015. Disponível em: <http://ead.ifrn.edu.br/portal/wp-content/uploads/2016/02/Artigo411.pdf>. Acesso em: 02 mai. 2016.

VILAÇA, M. L. C. Pesquisa e ensino: considerações e reflexões. Revista E-scrita: revista do curso de letras da UNIABEU, v. 1, n. 2, p. 59-74, maio/ago. 2010. Disponível em: $<$ http://www.uniabeu.edu.br/publica/index.php/RE/article/viewFile/26/pdf_23>. Acesso em: 10 mar. 2016. 


\section{APÊNDICE A - RELAÇÃO DE DOCUMENTOS DE PESQUISA}

\begin{tabular}{|c|c|c|c|c|}
\hline $\begin{array}{l}\text { Código do } \\
\text { documento }\end{array}$ & Documento & $\begin{array}{c}\text { Finalidade e/ou principais } \\
\text { informações }\end{array}$ & $\begin{array}{l}\text { Expedição } \\
\text { e/ou vigência }\end{array}$ & $\begin{array}{l}\text { Coleta e/ou } \\
\text { disponível }\end{array}$ \\
\hline Doc 1 & $\begin{array}{l}\text { Plano de } \\
\text { Desenvolvimento } \\
\text { Institucional do } \\
\text { IFB }\end{array}$ & $\begin{array}{l}\text { O PDI consiste num } \\
\text { documento em que se } \\
\text { definem a missão da } \\
\text { instituição de ensino } \\
\text { superior e as estratégias para } \\
\text { atingir suas metas e } \\
\text { objetivos. }\end{array}$ & $\begin{array}{l}2009, \\
\text { quinquenal, de } \\
2009 \text { a } 2013\end{array}$ & $\begin{array}{l}\text { Internet, } \\
\text { www.ifb.edu.br }\end{array}$ \\
\hline Doc 2 & $\begin{array}{l}\text { Planejamento } \\
\text { Institucional IFB } \\
2009\end{array}$ & $\begin{array}{l}\text { Documento norteador do } \\
\text { planejamento estratégico } \\
\text { anual da instituição }\end{array}$ & 2009 , anual & $\begin{array}{l}\text { Internet, } \\
\text { www.ifb.edu.br }\end{array}$ \\
\hline Doc 3 & $\begin{array}{l}\text { Planejamento } \\
\text { Institucional IFB } \\
2010 \\
\end{array}$ & $\begin{array}{l}\text { Documento norteador do } \\
\text { planejamento estratégico } \\
\text { anual da instituição }\end{array}$ & 2010, anual & $\begin{array}{l}\text { Internet, } \\
\text { www.ifb.edu.br }\end{array}$ \\
\hline Doc 4 & $\begin{array}{l}\text { Planejamento } \\
\text { Institucional IFB } \\
2011\end{array}$ & $\begin{array}{l}\text { Documento norteador do } \\
\text { planejamento estratégico } \\
\text { anual da instituição }\end{array}$ & 2011 , anual & $\begin{array}{l}\text { Internet, } \\
\text { www.ifb.edu.br }\end{array}$ \\
\hline Doc 5 & $\begin{array}{l}\text { Planejamento } \\
\text { Institucional IFB } \\
2012\end{array}$ & $\begin{array}{l}\text { Documento norteador do } \\
\text { planejamento estratégico } \\
\text { anual da instituição }\end{array}$ & 2012 , anual & $\begin{array}{l}\text { Internet, } \\
\text { www.ifb.edu.br }\end{array}$ \\
\hline Doc 6 & $\begin{array}{l}\text { Planejamento } \\
\text { Institucional IFB } \\
2013 \\
\end{array}$ & $\begin{array}{l}\text { Documento norteador do } \\
\text { planejamento estratégico } \\
\text { anual da instituição }\end{array}$ & 2013 , anual & $\begin{array}{l}\text { Internet, } \\
\text { www.ifb.edu.br }\end{array}$ \\
\hline Doc 7 & $\begin{array}{l}\text { Relatório de } \\
\text { Gestão IFB } 2009\end{array}$ & $\begin{array}{l}\text { Documento apresentado aos } \\
\text { órgãos de controle como } \\
\text { prestação de contas anual. }\end{array}$ & 2010, anual & $\begin{array}{l}\text { Internet, } \\
\text { www.ifb.edu.br }\end{array}$ \\
\hline Doc 8 & $\begin{array}{l}\text { Relatório de } \\
\text { Gestão IFB } 2010\end{array}$ & $\begin{array}{l}\text { Documento apresentado aos } \\
\text { órgãos de controle como } \\
\text { prestação de contas anual. }\end{array}$ & 2011 , anual & $\begin{array}{l}\text { Internet, } \\
\text { www.ifb.edu.br }\end{array}$ \\
\hline Doc 9 & $\begin{array}{l}\text { Relatório de } \\
\text { Gestão IFB } 2011\end{array}$ & $\begin{array}{l}\text { Documento apresentado aos } \\
\text { órgãos de controle como } \\
\text { prestação de contas anual. }\end{array}$ & 2012, anual & $\begin{array}{l}\text { Internet, } \\
\text { www.ifb.edu.br }\end{array}$ \\
\hline Doc 10 & $\begin{array}{l}\text { Relatório de } \\
\text { Gestão IFB } 2012\end{array}$ & $\begin{array}{l}\text { Documento apresentado aos } \\
\text { órgãos de controle como } \\
\text { prestação de contas anual. }\end{array}$ & 2013, anual & $\begin{array}{l}\text { Internet, } \\
\text { www.ifb.edu.br }\end{array}$ \\
\hline Doc 11 & $\begin{array}{l}\text { Relatório de } \\
\text { Gestão IFB } 2013\end{array}$ & $\begin{array}{l}\text { Documento apresentado aos } \\
\text { órgãos de controle como } \\
\text { prestação de contas anual. }\end{array}$ & 2014 , anual & $\begin{array}{l}\text { Internet, } \\
\text { www.ifb.edu.br }\end{array}$ \\
\hline Doc 12 & $\begin{array}{l}\text { Termo de } \\
\text { Acordo de Metas } \\
\text { (TAM) }\end{array}$ & $\begin{array}{l}\text { Compromisso de } \\
\text { responsabilidades firmando } \\
\text { entre o MEC e o IFB. }\end{array}$ & $\begin{array}{l}2009 \\
\text { anos }\end{array}$ & $\begin{array}{l}\text { Internet, } \\
\text { www.ifb.edu.br }\end{array}$ \\
\hline
\end{tabular}

